4

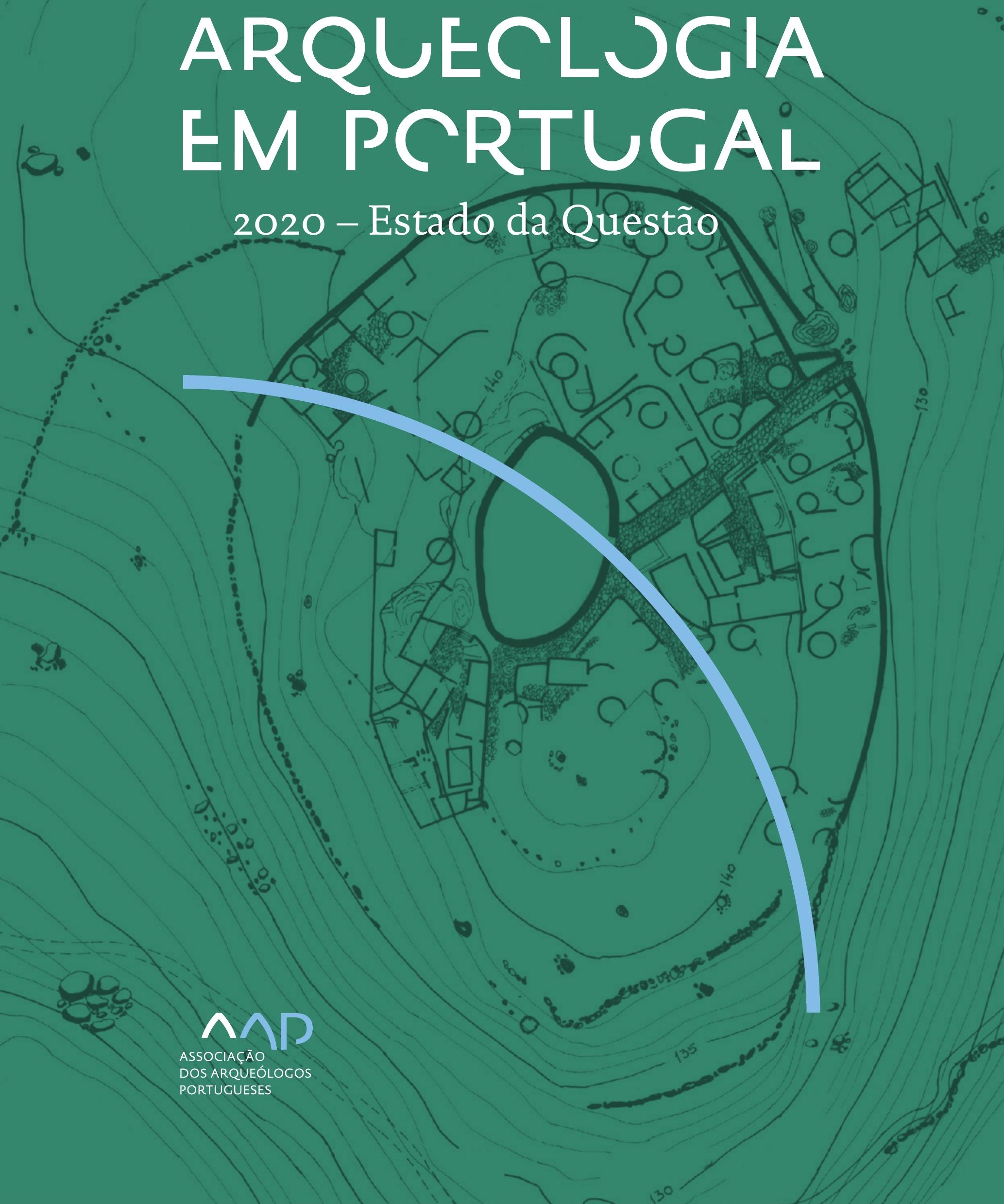


Coordenação editorial: José Morais Arnaud, César Neves e Andrea Martins Design gráfico: Flatland Design

AAP - ISBN: 978-972-9451-89-8

CITCEM - ISBN: 978-989-8970-25-1

Associação dos Arqueólogos Portugueses e CITCEM

Lisboa, 2020

O conteúdo dos artigos é da inteira responsabilidade dos autores. Sendo assim a Associação dos Arqueólogos Portugueses declina qualquer responsabilidade por eventuais equívocos ou questões de ordem ética e legal.

Desenho de capa:

Planta do castro de Monte Mozinho (Museu Municipal de Penafiel).

\section{$\hat{\wedge} \mathrm{P}$}

DOS ARQUEÓLOGOS PORTUGUESES

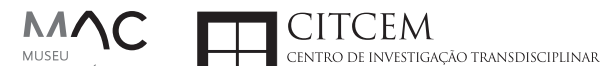
MUSEU
ARQUELLÓGICO
DO CARMO
U.PORTO

FLUP FACULDADE DE LETRAS
UNIVERSIDADE DO PORTO

Apoio

EC para a Ciência 


\section{Índice}

15 Prefácio

José Morais Arnaud

\section{Historiografia e Teoria}

17 Território, comunidade, memória e emoção: a contribuição da história da arqueologia (algumas primeiras e breves reflexões)

Ana Cristina Martins

25 Como descolonizar a arqueologia portuguesa?

Rui Gomes Coelho

41 Arqueologia e Modernidade: uma revisitação pessoal e breve de alguns aspetos da obra homónima de Julian Thomas de 2004

Vítor Oliveira Jorge

57 Dados para a História das Mulheres na Arqueologia portuguesa, dos finais do século XIX aos inícios do século XX: números, nomes e tabelas

Filipa Dimas / Mariana Diniz

73 Retractos da arqueologia portuguesa na imprensa: (in)visibilidades no feminino

Catarina Costeira / Elsa Luís

85 Arqueologia e Arqueólogos no Norte de Portugal Jacinta Bugalhão

101 Vieira Guimarães (1864-1939) e a arqueologia em Tomar: uma abordagem sobre o território e as gentes

João Amendoeira Peixoto / Ana Cristina Martins

115 Os memoráveis? A arqueologia algarvia na imprensa nacional e regional na presente centúria (2001-2019): características, visões do(s) passado(s) e a arqueologia

enquanto marca

Frederico Agosto / João Silva

129 A Evolução da Arqueologia Urbana e a Valorização Patrimonial no Barlavento Algarvio: Os casos de Portimão e Silves

Artur Mateus / Diogo Varandas / Rafael Boavida

\section{Gestão, Valorização e Salvaguarda do Património}

145 O Caderno Reivindicativo e as condições de trabalho em Arqueologia Miguel Rocha / Liliana Matias Carvalho / Regis Barbosa / Mauro Correia / Sara Simões / Jacinta Bugalhão / Sara Brito / Liliana Veríssimo Carvalho / Richard Peace / Pedro Peça / Cézer Santos

155 Os Estudos de Impacte Patrimonial como elemento para uma estratégia sustentável de minimização de impactes no âmbito de reconversões agrícolas Tiago do Pereiro

165 Salvaguarda de Património arqueológico em operações florestais: gestão e sensibilização Filipa Bragança / Gertrudes Zambujo / Sandra Lourenço / Belém Paiva / Carlos Banha / Frederico Tatá Regala / Helena Moura / Jacinta Bugalhão / João Marques / José Correia / Pedro Faria / Samuel Melro

179 Os valores do Património: uma investigação sobre os Sítios Pré-históricos de Arte Rupestre do Vale do Rio Côa e de Siega Verde José Paulo Francisco 
189 Conjugando recursos arqueológicos e naturais para potenciar as visitas ao Geoparque Litoral de Viana do Castelo (Noroeste de Portugal)

Hugo A. Sampaio / Ana M.S. Bettencourt / Susana Marinho / Ricardo Carvalhido

203 Áreas de Potencial Arqueológico na Região do Médio Tejo: Modelo Espacial Preditivo Rita Ferreira Anastácio / Ana Filipa Martins / Luiz Oosterbeek

223 Património Arqueológico e Gestão Territorial: O contributo da Arqueologia para a revisão do PDM de Avis

Ana Cristina Ribeiro

237 A coleção arqueológica do extinto Museu Municipal do Porto - Origens, Percursos e Estudos

Sónia Couto

251 Valpaços - uma nova carta arqueológica

Pedro Pereira / Maria de Fátima Casares Machado

263 Arqueologia na Cidade de Peniche

Adriano Constantino / Luís Rendeiro

273 Arqueologia Urbana: a cidade de Lagos como caso de Estudo Cátia Neto

285 Estratégias de promoção do património cultural subaquático nos Açores. O caso da ilha do Faial

José Luís Neto / José Bettencourt / Luís Borges / Pedro Parreira

297 Carta Arqueológica da Cidade Velha: Uma primeira abordagem

Jaylson Monteiro / Nireide Tavares / Sara da Veiga / Claudino Ramos / Edson Brito /

Carlos Carvalho / Francisco Moreira / Adalberto Tavares

311 Antropologia Virtual: novas metodologias para a análise morfológica e funcional Ricardo Miguel Godinho / Célia Gonçalves

\section{Didáctica da Arqueologia}

327 Como os projetos de Arqueologia podem contribuir para uma comunidade culturalmente mais consciente Alexandra Figueiredo / Claúdio Monteiro / Adolfo Silveira / Ricardo Lopes

337 Educação Patrimonial - Um cidadão esclarecido é um cidadão ativo! Ana Paula Almeida

351 A aproximação da Arqueologia à sala de aula: um caso de estudo no $3^{\circ}$ ciclo do Ensino Básico Luís Serrão Gil

363 Arqueologia 3.o - Pensar e comunicar a Arqueologia para um futuro sustentável Mónica Rolo

377 “Conversa de Arqueólogos" - Divulgar a Arqueologia em tempos de Pandemia Diogo Teixeira Dias

389 Escola Profissional de Arqueologia: desafios e oportunidades Susana Nunes / Dulcineia Pinto / Júlia Silva / Ana Mascarenhas

399 Os Museus de Arqueologia e os Jovens: a oferta educativa para o público adolescente Beatriz Correia Barata / Leonor Medeiros

411 O museu universitário como mediador entre a ciência e a sociedade: o exemplo da secção de arqueologia no Museu de História Natural e da Ciência da Universidade do Porto (MHNC-UP)

Rita Gaspar 
421 Museu de Lanifícios: Real Fábrica de Panos. Atividades no âmbito da Arqueologia Beatriz Correia Barata / Rita Salvado

427 Arqueologia Pública e o caso da localidade da Mata (Torres Novas) Cláudia Manso / Ana Rita Ferreira / Cristiana Ferreira / Vanessa Cardoso Antunes

431 Do sítio arqueológico ao museu: um percurso (também) didático Lídia Fernandes

447 Estão todos convidados para a Festa! E para dançar também... O projecto do Serviço Educativo do Museu Arqueológico do Carmo na $5^{\underline{a}}$ Edição da Festa da Arqueologia Rita Pires dos Santos

459 O “Clã de Carenque”, um projeto didático de arqueologia Eduardo Gonzalez Rocha

469 Mediação cultural: peixe que puxa carroça nas Ruínas Romanas de Troia Inês Vaz Pinto / Ana Patrícia Magalhães / Patrícia Brum / Filipa Santos

481 Didática Arqueológica, experiências do Projeto Mértola Vila Museu Maria de Fátima Palma / Clara Rodrigues / Susana Gómez / Lígia Rafael

\section{Arte Rupestre}

497 Os inventários de arte rupestre em Portugal Mila Simões de Abreu

513 O projeto FIRST-ART - conservação, documentação e gestão das primeiras manifestações de arte rupestre no Sudoeste da Península Ibérica: as grutas do Escoural e Maltravieso Sara Garcês / Hipólito Collado / José Julio García Arranz / Luiz Oosterbeek / António Carlos Silva / Pierluigi Rosina / Hugo Gomes / Anabela Borralheiro Pereira / George Nash / Esmeralda Gomes / Nelson Almeida / Carlos Carpetudo

523 Trabalhos de documentação de arte paleolítica realizados no âmbito do projeto PalæoCôa André Tomás Santos / António Fernando Barbosa / Luís Luís / Marcelo Silvestre / Thierry Aubry

537 Imagens fantasmagóricas, silhuetas elusivas: as figuras humanas na arte do Paleolítico Superior da região do Côa Mário Reis

$55^{1}$ Os motivos zoomórficos representados nas placas de tear de Vila Nova de São Pedro (Azambuja, Portugal) Andrea Martins / César Neves / José M. Arnaud / Mariana Diniz

571 Arte Rupestre do Monte de Góios (Lanhelas, Caminha). Síntese dos resultados dos trabalhos efectuados em 2007-2009 Mário Varela Gomes

599 Gravuras rupestres de barquiformes no Monte de S. Romão, Guimarães, Noroeste de Portugal Daniela Cardoso

613 Círculos segmentados gravados na Bacia do Rio Lima (Noroeste de Portugal): contributos para o seu estudo Diogo Marinho / Ana M.S. Bettencourt / Hugo Aluai Sampaio

631 Equídeos gravados no curso inferior do Rio Mouro, Monção (NW Portugal). Análise preliminar Coutinho, L.M. / Bettencourt, A.M.S / Sampaio, Hugo A.S

645 Paletas na Arte Rupestre do Noroeste de Portugal. Inventário preliminar Bruna Sousa Afonso / Ana M. S. Bettencourt / Hugo A. Sampaio 


\section{Pré-História}

661 O projeto Miño/Minho: balanço de quatro anos de trabalhos arqueológicos Sérgio Monteiro-Rodrigues / João Pedro Cunha-Ribeiro / Eduardo Méndez-Quintas / Carlos Ferreira / Pedro Xavier / José Meireles / Alberto Gomes / Manuel Santonja / Alfredo Pérez-González

677 A ocupação paleolítica da margem esquerda do Baixo Minho: a indústria lítica do sítio de Pedreiras 2 (Monção, Portugal) e a sua integração no contexto regional Carlos Ferreira / João Pedro Cunha-Ribeiro / Sérgio Monteiro-Rodrigues / Eduardo Méndez-Quintas / Pedro Xavier / José Meireles / Alberto Gomes / Manuel Santonja / Alfredo Pérez-González

693 O sítio acheulense do Plistocénico médio da Gruta da Aroeira Joan Daura / Montserrat Sanz / Filipa Rodrigues / Pedro Souto / João Zilhão

703 As sociedades neandertais no Barlavento algarvio: modelos preditivos com recurso aos SIG

Daniela Maio

715 A utilização de quartzo durante o Paleolítico Superior no território dos vales dos rios Vouga e Côa

Cristina Gameiro / Thierry Aubry / Bárbara Costa / Sérgio Gomes / Luís Luís / Carmen Manzano / André Tomás Santos

733 Uma perspetiva diacrónica da ocupação do concheiro do Cabeço da Amoreira (Muge, Portugal) a partir da tecnologia lítica Joana Belmiro / João Cascalheira / Célia Gonçalves

745 Novos dados sobre a Pré-história Antiga no concelho de Palmela. A intervenção arqueológica no sítio do Poceirão I

Michelle Teixeira Santos

757 Problemas em torno de Datas Absolutas Pré-Históricas no Norte do Alentejo Jorge de Oliveira

771 Povoamento pré-histórico nas áreas montanhosas do NO de Portugal: o Abrigo 1 de Vale de Cerdeira Pedro Xavier / José Meireles / Carlos Alves

783 Apreciação do povoamento do Neolítico Inicial na Baixa Bacia do Douro. A Lavra I (Serra da Aboboreira) como caso de estudo Maria de Jesus Sanches

797 O Processo de Neolitização na Plataforma do Mondego: os dados do Sector C do Outeiro dos Castelos de Beijós (Carregal do Sal)

João Carlos de Senna-Martinez / José Manuel Quintã Ventura / Andreia Carvalho / Cíntia Maurício

823 Novos trabalhos na Lapa da Bugalheira (Almonda, Torres Novas) Filipa Rodrigues / Pedro Souto / Artur Ferreira / Alexandre Varanda / Luís Gomes / Helena Gomes / João Zilhão

837 A pedra polida e afeiçoada do sítio do Neolítico médio da Moita do Ourives (Benavente, Portugal)

César Neves

857 Casal do Outeiro (Encarnação, Mafra): novos contributos para o conhecimento do povoamento do Neolítico final na Península de Lisboa.

Cátia Delicado / Carlos Maneira e Costa / Marta Miranda / Ana Catarina Sousa

873 Stresse infantil, morbilidade e mortalidade no sítio arqueológico do Neolítico Final/ Calcolítico ( $4^{\circ}$ e $3^{\circ}$ milénio a.C.) do Monte do Carrascal 2 (Ferreira do Alentejo, Beja) Liliana Matias de Carvalho / Sofia N. Wasterlain 
885 Come together: O Conjunto Megalítico das Motas (Monção, Viana do Castelo) e as expressões Campaniformes do Alto Minho Ana Catarina Basílio / Rui Ramos

899 Trabalhos arqueológicos no sítio Calcolítico da Pedreira do Poio Carla Magalhães / João Muralha / Mário Reis / António Batarda Fernandes

913 O sítio arqueológico de Castanheiro do Vento. Da arquitectura do sítio à arquitectura de um território João Muralha Cardoso

925 Estudo zooarqueológico das faunas do Calcolítico final de Vila Nova de São Pedro (Azambuja, Portugal): Campanhas de 2017 e 2018 Cleia Detry / Ana Catarina Francisco / Mariana Diniz / Andrea Martins / César Neves / José Morais Arnaud

943 As faunas depositadas no Museu Arqueológico do Carmo provenientes de Vila Nova de São Pedro (Azambuja): as campanhas de 1937 a 1967 Ana Catarina Francisco / Cleia Detry / César Neves / Andrea Martins / Mariana Diniz / José Morais Arnaud

959 Análise funcional de material lítico em sílex do castro de Vila Nova de S. Pedro (Azambuja, Portugal): uma primeira abordagem Rafael Lima

971 O recinto da Folha do Ouro 1 (Serpa) no contexto dos recintos de fossos calcolíticos alentejanos

António Carlos Valera / Tiago do Pereiro / Pedro Valério / António M. Monge Soares

\section{Proto-História}

987 Produção de sal marinho na Idade do Bronze do noroeste Português. Alguns dados para uma reflexão

Ana M. S. Bettencourt / Sara Luz / Nuno Oliveira / Pedro P. Simões / Maria Isabel C. Alves / Emílio Abad-Vidal

1001 A estátua-menir do Pedrão ou de São Bartolomeu do Mar (Esposende, noroeste de Portugal) no contexto arqueológico da fachada costeira de entre os rios Neiva e Cávado Ana M. S. Bettencourt / Manuel Santos-Estévez / Pedro Pimenta Simões / Luís Gonçalves

1015 O Castro do Muro (Vandoma/Baltar, Paredes) - notas para uma biografia de ocupação da Idade do Bronze à Idade Média

Maria Antónia D. Silva / Ana M. S. Bettencourt / António Manuel S. P. Silva / Natália Félix

1031 Do Bronze Final à Idade Média - continuidades e hiatos na ocupação de Povoados em Oliveira de Azeméis João Tiago Tavares / Adriaan de Man

1041 As faunas do final da Idade do Bronze no Sul de Portugal: leituras desde o Outeiro do Circo (Beja)

Nelson J. Almeida / Íris Dias / Cleia Detry / Eduardo Porfírio / Miguel Serra

1055 A Espada do Monte das Oliveiras (Serpa) - uma arma do Bronze Pleno do Sudoeste Rui M. G. Monge Soares / Pedro Valério / Mariana Nabais / António M. Monge Soares

1065 São Julião da Branca (Albergaria-a-Velha) - Investigação e valorização de um povoado do Bronze Final

António Manuel S. P. Silva / Paulo A. P. Lemos / Sara Almeida e Silva / Edite Martins de Sá

1083 Do castro de S. João ao Mosteiro de Santa Clara: notícia de uma intervenção arqueológica, em Vila do Conde Rui Pinheiro 
1095 O castro de Ovil (Espinho), um quarto de século de investigação - resultados e questões em aberto

Jorge Fernando Salvador / António Manuel S. P. Silva

1111 O Castro de Salreu (Estarreja), um povoado proto-histórico no litoral do Entre Douro e Vouga

Sara Almeida e Silva / António Manuel S. P. Silva / Paulo A. P. Lemos / Edite Martins de Sá

1127 Castro de Nossa Senhora das Necessidades (Sernancelhe): uma primeira análise artefactual Telma Susana O. Ribeiro

${ }_{1141}$ A cividade de Bagunte. O estado atual da investigação Pedro Brochado de Almeida

1153 Zoomorfos na cerâmica da Idade do Ferro no NW Peninsular: inventário, cronologias e significado Nuno Oliveira / Cristina Seoane

1163 Vasos gregos em Portugal: diferentes maneiras de contar a história do intercâmbio cultural na Idade do Ferro

Daniela Ferreira

1175 Os exotica da necrópole da Idade do Ferro do Olival do Senhor dos Mártires (Alcácer do Sal) no seu contexto regional

Francisco B. Gomes

\section{Antiguidade Clássica e Tardia}

1191 O uso de madeira como combustível no sítio da Quinta de Crestelos (Baixo Sabor): da Idade do Ferro à Romanização Filipe Vaz / João Tereso / Sérgio Simões Pereira / José Sastre / Javier Larrazabal Galarza / Susana Cosme / José António Pereira / Israel Espi

1207 Cultivos de Época Romana no Baixo Sabor: continuidade em tempos de mudança? João Pedro Tereso / Sérgio Simões Pereira / Filipe Santos / Luís Seabra / Filipe Vaz

1221 A casa romana na Hispânia: aplicação dos modelos itálicos nas províncias ibéricas Fernanda Magalhães / Diego Machado / Manuela Martins

1235 As pinturas murais romanas da Rua General Sousa Machado, n. ${ }^{5}$ 1, Chaves José Carvalho

1243 Trás do Castelo (Vale de Mir, Pegarinhos, Alijó) - Uma exploração agrícola romana do Douro

Tony Silvino / Pedro Pereira

1255 A sequência de ocupação no quadrante sudeste de Bracara Augusta: as transformações de uma unidade doméstica Lara Fernandes / Manuela Martins

1263 Os Mosaicos com decoração geométrica e geométrico-vegetalista dos sítios arqueológicos da área do Conuentus Bracaraugustanus. Novas abordagens quanto à conservação, restauro, decoração e datação Maria de Fátima Abraços / Licínia Wrench

1277 “Casa Romana” do Castro de São Domingos (Cristelos, Lousada): Escavação, Estudo e Musealização Paulo André de P. Lemos

1291 A arqueobotânica no Castro de Guifões (Matosinhos, Noroeste de Portugal): O primeiro estudo carpológico

Luís Seabra / Andreia Arezes / Catarina Magalhães / José Varela / João Pedro Tereso 
1305 Um Horreum Augustano na Foz do Douro (Monte do Castelo de Gaia, Vila Nova de Gaia) Rui Ramos

1311 Ponderais romanos na Lusitânia: padrões, formas, materiais e contextos de utilização Diego Barrios Rodríguez

1323 Um almofariz centro-itálico na foz do Mondego

Marco Penajoia

1335 Estruturas romanas de Carnide - Lisboa Luísa Batalha / Mário Monteiro / Guilherme Cardoso

1347 O contexto funerário do sector da "necrópole NO" da Rua das Portas de S. Antão (Lisboa): o espaço, os artefactos, os indivíduos e a sua interconectividade na interpretação do passado Sílvia Loja, José Carlos Quaresma, Nelson Cabaço, Marina Lourenço, Sílvia Casimiro, Rodrigo Banha da Silva, Francisca Alves-Cardoso

${ }_{1361}$ Povoamento em época Romana na Amadora - resultados de um projeto pluridisciplinar Gisela Encarnação / Vanessa Dias

1371 A Arquitectura Residencial em Mirobriga (Santiago do Cacém): contributo a partir de um estudo de caso Filipe Sousa / Catarina Felício

${ }_{1385}$ O fim do ciclo. Saneamento e gestão de resíduos nos edifícios termais de Mirobriga (Santiago do Cacém)

Catarina Felício / Filipe Sousa

1399 Balsa, Topografia e Urbanismo de uma Cidade Portuária Vítor Silva Dias / João Pedro Bernardes / Celso Candeias / Cristina Tété Garcia

1413 No Largo das Mouras Velhas em Faro (2017): novas evidências da necrópole norte de Ossonoba e da sua ocupação medieval Ricardo Costeira da Silva / Paulo Botelho / Fernando Santos / Liliana Nunes

1429 Instrumentos de pesca recuperados numa fábrica de salga em Ossonoba (Faro) Inês Rasteiro / Ricardo Costeira da Silva / Paulo Botelho

1439 A Necrópole Romana do Eirô, Duas Igrejas (Penafiel): intervenção arqueológica de 2016 Laura Sousa / Teresa Soeiro

1457 Ritual, descarte ou afetividade? A presença de Canis lupus familiaris na Necrópole Noroeste de Olisipo (Lisboa)

Beatriz Calapez Santos / Sofia Simões Pereira / Rodrigo Banha da Silva / Sílvia Casimiro / Cleia Detry / Francisca Alves Cardoso

1467 Dinâmicas económicas em Bracara na Antiguidade Tardia Diego Machado / Manuela Martins / Fernanda Magalhães / Natália Botica

1479 Cerâmicas e Vidros da Antiguidade Tardia do Edifício sob a Igreja do Bom Jesus (Vila Nova de Gaia) Joaquim Filipe Ramos

1493 Novos contributos para a topografia histórica de Mértola no período romano e na Antiguidade Tardia Virgílio Lopes

\section{8. Época Medieval}

1511 Cerâmicas islâmicas no Garb setentrional "português": algumas evidências e incógnitas Constança dos Santos / Helena Catarino / Susana Gómez / Maria José Gonçalves / Isabel Inácio / Gonçalo Lopes / Jacinta Bugalhão / Sandra Cavaco / Jaquelina Covaneiro / Isabel Cristina Fernandes / Ana Sofia Gomes 
1525 Contributo para o conhecimento da cosmética islâmica, em Silves, durante a Idade Média Rosa Varela Gomes

1537 Yábura e o seu território - uma análise histórico-arqueológica de Évora entre os séculos VIII-XII José Rui Santos

1547 A encosta sul do Castelo de Palmela - resultados preliminares da escavação arqueológica Luís Filipe Pereira / Michelle Teixeira Santos

1559 A igreja de São Lourenço (Mouraria, Lisboa): um conjunto de silos e de cerâmica medieval islâmica

Andreia Filipa Moreira Rodrigues

1571 O registo material de movimentações populacionais no Médio Tejo, durante os séculos XII-XIII. Dois casos de "sunken featured buildings", nos concelhos de Cartaxo e Torres Novas Marco Liberato / Helena Santos / Nuno Santos

1585 O nordeste transmontano nos alvores da Idade média. Notas para reflexão Ana Maria da Costa Oliveira

1601 Sepulturas escavadas na rocha do Norte de Portugal e do Vale do Douro: primeiros resultados do Projecto SER-NPVD

Mário Jorge Barroca / César Guedes / Andreia Arezes / Ana Maria Oliveira

1619 "Portucalem Castrum Novum" entre o Mediterrâneo e o Atlântico: o estudo dos materiais cerâmicos alto-medievais do arqueossítio da rua de D. Hugo, nํ. 5 (Porto) João Luís Veloso

1627 A Alta Idade Média na fronteira de Lafões: notas preliminares sobre a Arqueologia no Concelho de Vouzela

Manuel Luís Real / Catarina Tente

1641 Um conjunto cerâmico medieval fora de portas: um breve testemunho aveirense Susana Temudo

${ }_{1651}$ Os Lóios do Porto: uma perspetiva integrada no panorama funerário da Baixa Idade Média à Época Moderna em meios urbanos em Portugal

Ana Lema Seabra

1659 O Caminho Português Interior de Santiago como eixo viário na Idade Média Pedro Azevedo

1665 Morfologia Urbana: Um exercício em torno do Castelo de Ourém André Donas-Botto / Jaqueline Pereira

1677 Intervenção arqueológica na Rua Marquês de Pombal/Largo do Espírito Santo (Bucelas, Loures)

Florbela Estêvão / Nathalie Antunes-Ferreira / Dário Ramos Neves / Inês Lisboa

1691 O Cemitério Medieval do Poço do Borratém e a espacialidade funerária na cidade de Lisboa Inês Belém / Vanessa Filipe / Vasco Noronha Vieira / Sónia Ferro / Rodrigo Banha da Silva

1705 Um Espaço Funerário Conventual do séc. XV em Lisboa: o caso do Convento de São Domingos da Cidade Sérgio Pedroso / Sílvia Casimiro / Rodrigo Banha da Silva / Francisca Alves Cardoso

\section{9. Época Moderna e Contemporânea}

1721 Arqueologia Moderna em Portugal: algumas reflexões críticas em torno da quantificação de conjuntos cerâmicos e suas inferências históricas e antropológicas Rodrigo Banha da Silva / André Bargão / Sara da Cruz Ferreira

1733 Faianças de dois contextos entre os finais do século XVI e XVIII do Palácio dos Condes de Penafiel, Lisboa

Martim Lopes / Tomás Mesquita 
1747 Um perfil de consumo do século XVIII na foz do Tejo: O caso do Mercado da Ribeira, Lisboa Sara da Cruz Ferreira / Rodrigo Banha da Silva / André Bargão

1761 Os Cachimbos dos Séculos XVII e XVIII do Palácio Mesquitela e Convento dos Inglesinhos (Lisboa)

Inês Simão / Marina Pinto / João Pimenta / Sara da Cruz Ferreira / André Bargão / Rodrigo Banha da Silva

1775 "Tomar os fumos da erua que chamão em Portugal erua sancta». Estudo de Cachimbos provenientes da Rua do Terreiro do Trigo, Lisboa

Miguel Martins de Sousa / José Pedro Henriques / Vanessa Galiza Filipe

1787 Cachimbos de Barro Caulínitico da Sé da Cidade Velha (República de Cabo Verde)

Rodrigo Banha da Silva / João Pimenta / Clementino Amaro

1801 Algumas considerações sobre espólio não cerâmico recuperado no Largo de Jesus (Lisboa) Carlos Boavida

1815 Adereços de vidro, dos séculos XVI-XVIII, procedentes do antigo Convento de Santana de Lisboa (anéis, braceletes e contas)

Joana Gonçalves / Rosa Varela Gomes / Mário Varela Gomes

1837 Da ostentação, luxo e poder à simplicidade do uso quotidiano: arqueologia e simbologia de joias e adornos da Idade Moderna Portuguesa Jéssica Iglésias

1849 Os amuletos em Portugal - dos objetos às superstições: o coral vermelho Alexandra Vieira

1865 Cerâmicas de Vila Franca de Xira nos séculos XV e XVI Eva Pires

1879 «Não passa por teu o que me pertence». Marcas de individualização associadas a faianças do Convento de Nossa Senhora de Aracoeli, Alcácer do Sal Catarina Parreira / Íris Fragoso / Miguel Martins de Sousa

1891 Cerâmica de Leiria: alguns focos de produção

Jaqueline Pereira / André Donas-Botto

1901 Os Fornos na Rua da Biquinha, em Óbidos Hugo Silva / Filipe Oliveira

1909 A casa de Pêro Fernandes, contador dos contos de D. Manuel I: o sítio arqueológico da Silha do Alferes, Seixal (século XVI) Mariana Nunes Ferreira

1921 O Alto da Vigia (Sintra) e a vigilância e defesa da costa Alexandre Gonçalves / Sandra Santos

1937 O contexto da torre sineira da Igreja de Santa Maria de Loures Paulo Calaveira / Martim Lopes

1949 A Necrópole do Hospital Militar do Castelo de São Jorge e as práticas funerárias na Lisboa de Época Moderna Susana Henriques / Liliana Matias de Carvalho / Ana Amarante / Sofia N. Wasterlain

1963 SAND - Sarilhos Grandes Entre dois Mundos: o adro da Igreja e a Paleobiologia dos ossos humanos recuperados

Paula Alves Pereira / Roger Lee Jesus / Bruno M. Magalhães

1975 Expansão urbana da vila de Cascais no século XVII e XVIII: a intervenção arqueológica na Rua da Vitória no 15 a 17

Tiago Pereira / Vanessa Filipe

1987 Novos dados para o conhecimento do Urbanismo de Faro em época Moderna Ana Rosa 
1995 Um exemplo de Arqueologia Urbana em Alcoutim: o Antigo Edifício dos CTT Marco Fernandes / Marta Dias / Alexandra Gradim / Virgílio Lopes / Susana Gómez Martínez

2007 Palácio dos Ferrazes (Rua das Flores/Rua da Vitória, Porto): a cocheira de Domingos Oliveira Maia

Francisco Raimundo

2021 As muitas vidas de um edifício urbano: História, Arqueologia e Antropologia no antigo Recreatório Paroquial de Penafiel Helena Bernardo / Jorge Sampaio / Marta Borges

2035 O convento de Nossa Senhora da Esperança de Ponta Delgada: o contributo da arqueologia para o conhecimento de um monumento identitário João Gonçalves Araújo / N’Zinga Oliveira

2047 Arqueologia na ilha do Corvo... em busca da capela de Nossa Senhora do Rosário Tânia Manuel Casimiro / José Luís Neto / Luís Borges / Pedro Parreira

2059 Perdidos à vista da Costa. Trabalhos arqueológicos subaquáticos na Barra do Tejo Jorge Freire / José Bettencourt / Augusto Salgado

2071 Arqueologia marítima em Cabo Verde: enquadramento e primeiros resultados do projecto CONCHA

José Bettencourt / Adilson Dias / Carlos Lima / Christelle Chouzenoux / Cristóvão Fonseca / Dúnia Pereira / Gonçalo Lopes / Inês Coelho / Jaylson Monteiro / José Lima / Maria Eugénia Alves / Patrícia Carvalho / Tiago Silva

2085 Trabalhos arqueológicos na Cidade Velha (Ribeira Grande de Santiago, Cabo Verde): reflexões sobre um projecto de investigação e divulgação patrimonial André Teixeira / Jaylson Monteiro / Mariana Mateus / Nireide Tavares / Cristovão Fonseca / Gonçalo C. Lopes / Joana Bento Torres / Dúnia Pereira / André Bargão / Aurélie Mayer / Bruno Zélie / Carlos Lima / Christelle Chouzenoux / Inês Henriques / Inês Pinto Coelho / José Lima / Patrícia Carvalho / Tiago Silva

2103 A antiga fortificação de Quelba / Khor Kalba (E.A.U.). Resultados de quatro campanhas de escavações, problemáticas e perspectivas futuras Rui Carita / Rosa Varela Gomes / Mário Varela Gomes / Kamyar Kamyad

2123 Colónias para homens novos: arqueologia da colonização agrária fascista no noroeste ibérico Xurxo Ayán Vila / José Mạ . Señorán Martín 


\title{
AS FAUNAS DO FINAL DA IDADE DO BRONZE NO SUL DE PORTUGAL: LEITURAS DESDE O OUTEIRO DO CIRCO (BEJA)
}

\author{
Nelson J. Almeida ${ }^{1,}$, Íris Dias $^{1}$, Cleia Detry ${ }^{1}$, Eduardo Porfírio $^{2}$, Miguel Serra $^{3}$
}

\begin{abstract}
RESUMO
Apresentam-se os resultados da análise dos restos faunísticos do povoado do Bronze Final do Outeiro do Circo (Beja), ainda inéditos, provenientes sobretudo da fossa/silo da sondagem 3 e das sondagens 7 e 8 localizadas junto ao talude defensivo. As práticas cinegéticas são acessórias neste conjunto com predomínio de restos de ovelhas e cabras, seguidas por gado bovino e suíno. Os padrões de abate, com a presença de indivíduos jovens e adultos sugerem uma economia mista, assente em recursos primários e secundários. O estudo permitiu valorizar um conjunto bastante fragmentado e afectado por processos pós-deposicionais, mas com indicadores de acção antrópica relacionáveis com o processamento das carcaças sob a forma de marcas de corte e termo-alteração por queima.
\end{abstract}

Palavras-chave: Zooarqueologia, Tafonomia, Idade do Bronze, Povoado, Sudoeste Peninsular.

\begin{abstract}
We present the results obtained from the analysis of unpublished faunal remains from the Bronze Age settlement of Outeiro do Circo (Beja). The materials provenance is diverse, corresponding mainly to one pit/ silo from trench 3 and the areas near the defensive systems designated trench 7 and 8. Hunting strategies are complementary in the assemblage, with a predominance of sheep and goat remains, followed by cattle and swine. Kill-off patterns with the presence of young and adult individuals are suggestive of a mixed economy with the exploitation of primary and secondary resources. Although highly fragmented and affected by postdepositional processes it was possible to record several anthropization indicators related to the butchering process and thermo-alteration of remains by fire.
\end{abstract}

Keywords: Zooarchaeology, Taphonomy, Bronze Age, Settlement, Southwest Iberia.

\section{INTRODUÇÃO}

A análise da componente animal nas dietas da Idade do Bronze do Sul de Portugal é problemática, não apenas devido ao pequeno número de conjuntos faunísticos preservados, estudados e publicados, como às características próprias destas colecções, com um reduzido número de restos identificáveis taxonomicamente e uma alta afectação por processos pós-deposicionais que nem sempre são avaliados.

Foi recentemente realizado o estudo de uma amostra faunística do povoado do Outeiro do Circo (Beja),

\footnotetext{
1. Uniarq, Centro de Arqueologia da Universidade de Lisboa, Faculdade de Letras da Universidade de Lisboa.

2. Núcleo de Arqueologia da Câmara Municipal de Sintra. CEAACP - Centro de Estudos de Arqueologia, Artes e Ciências do Património.

3. Câmara Municipal de Serpa. CEAACP - Centro de Estudos de Arqueologia, Artes e Ciências do Património.

* Centro de Arqueologia da Universidade de Lisboa. Faculdade de Letras da Universidade de Lisboa, Alameda da Universidade, 160o-214, Lisboa, Portugal; nelsonjalmeida@gmail.com
} 
cronologicamente enquadrado no final da Idade do Bronze (Valério \& alii. 2013), que permitiu registar uma tendência para a preponderância de espécies domésticas face às selvagens, com similitudes ao que ocorre em outros conjuntos coevos (Dias $\mathbb{\&}$ alii, no prelo).

Com vista a alargar o leque de informações disponíveis procedemos à análise zooarqueológica de uma amostra que aqui apresentamos e que resulta dos trabalhos de escavação arqueológica decorridos no âmbito do projeto de investigação " $O$ povoado do Bronze Final do Outeiro do Circo (Beja)", que decorreu entre 2014 e 2017, integrando ainda uma pequena coleção de faunas recolhidas em $2013 \mathrm{em}$ projeto anterior.

\section{MATERIAIS E MÉTODOS}

\subsection{Materiais}

Os materiais em análise foram recolhidos nas sondagens 8 (33,6\%), 7 (31,7\%), $3(28,4 \%)$ e $1(6,3 \%)$ do Outeiro do Circo (Figura 1). Destacam-se pela sua relevância quantitativa a [303] da sondagem $3 \mathrm{com}$ 118 restos e as [707] e [708] da sondagem 7 com um total de 101 e 97 fragmentos respectivamente.

Da sondagem 1, que corresponde à muralha compósita identificada no sítio, foi analisado um pequeno conjunto inédito decorrente de actividades de limpeza posteriores com um total de 40 fragmentos faunísticos. De salientar que em estudos anteriores, cerca de $81 \%$ do material analisado era proveniente da sondagem 1 (Dias \& a alii, no prelo) pelo que o conjunto apresentado deverá ser entendido como complementar a essa análise (Figura 1).

Na sondagem 3, apesar da pequena potência estratigráfica foi identificada uma estrutura negativa/fossa [311] escavada no substrato geológico, com paredes irregulares de planta tendencionalmente circular e secção de morfologia oval. Os materiais analisados são provenientes da [302] e [303], níveis sucessivos de enchimento constituídos essencialmente por pedras envoltas num sedimento de cor negra, com presença de bastante cerâmica e alguma fauna. Outros materiais da [302] e [303] foram analisados por Dias $\&$ alii (no prelo) sendo que os restos desta sondagem correspondiam a cerca de $19 \%$ dessa amostra. $\mathrm{Na}$ sondagem 7 foram registados níveis de derrube da muralha adjacente, anteriormente intervencionada na Sondagem 1. As faunas correspondem maioritariamente à [707] e [708], com apenas dois fragmentos da [702]. Na [707] o estrato argiloso era muito compacto de coloração castanha bastante escura e com presença de nódulos desagregados do substrato geológico (gabro). Pedras de calibre pequeno, incluindo algumas aparentemente expostas ao fogo [708], preenchiam uma interface escavada no geológico [709] com aparente origem antrópica. Alguns carvões, cerâmica, fauna e barro cozido foram recuperados. As faunas desta sondagem são provenientes de depósitos não afectados pelos trabalhos agrícolas, sendo os materiais cerâmicos atribuíveis ao final da Idade do Bronze.

Quanto aos restos da sondagem 8, localizada próxima do talude defensivo, são provenientes de várias unidades estratigráficas, sobretudo das posicionadas na parte inferior da estratigrafia. Salienta-se a presença de raízes em várias unidades, assim como de pequenos nódulos de barro e carvões na [810], a qual englobava $19 \%$ dos restos desta sondagem e envolvia uma possível estrutura [815] composta por uma única fiada de pedras. A esta estavam encostados outros depósitos, como o [813] (25\% da fauna desta sondagem) onde se registaram nódulos de tonalidade esbranquiçada, cerâmica, fauna, barro e indústria lítica. É de referir que esta sondagem não se encontra terminada, pelo que algumas considerações relativas à atribuição cronológica das suas unidades estratigráficas não são totalmente seguras visto que, apesar de ainda não ter sido intervencionado, foi registado um nível com cerâmicas da Idade do Ferro na campanha de 2019, sendo que não incluímos nesta análise faunas dessa campanha.

\subsection{Métodos}

A análise dos restos arqueofaunísticos seguiu metodologias comuns em Zooarqueologia e Tafonomia (Lyman, 1994; Reitz \& Wing, 2008). A identificação taxonómica levou em conta a aquisição de dados biométricos e registo de características morfológicas de espécies similares, como Ovis aries e Capra hircus (Zeder $\mathbb{\&}$ Lapham, 2010; Zeder $\mathbb{\&}$ Pilaar, 2010). A obtenção de dados osteométricos e odontométricos foi realizada com um paquímetro digital Lux seguindo critérios de Driesch (1976) com acrescentos pontuais (e.g., Payne \& Bull, 1988; Davis, 1996).

Os padrões de idade implementados (infantil, juvenil/sub-adulto, adulto, senil) basearam-se em estimativas de desenvolvimento ósseo, erupção e desgaste dentário (e.g., Grant, 1982; Payne, 1987; Zeder, 2006; Lemoine $\mathbb{\&}$ alii., 2014; Zeder $\mathbb{\&}$ alii, 
2015). Mesmo que não passíveis de identificação taxonómica, todos os restos foram tentativamente associados a um grupo genérico de peso: muito pequeno ( $\mathrm{GP} 1 ;<2 \mathrm{og})$, pequeno $\left(\mathrm{GP}_{2} ; 20-100 \mathrm{~kg}\right)$, médio ( $\left.\mathrm{GP}_{3} ; 100-300 \mathrm{~kg}\right)$ e grande $\left(\mathrm{GP}_{4} ;>300 \mathrm{~kg}\right)$. Os resultados são apresentados através do Number of Specimens (NSP), Number of Identified Specimens (NISP), Minimum Number of Elements (MNE) e Minimum Number of Individuals (MNI) (Binford, 1984; Grayson, 1984).

Todos os restos foram agrupados em categorias de dimensão máxima e os fragmentos diafisários foram analisados de acordo com a sua completude (longitude e secção), delineação (curva, longitudinal, transversal), ângulo (oblíquo, recto, misto) e superfície (suave, irregular) dos planos de fractura (Villa \& Mahieu, 1991).

A análise macroscópica e microscópica foi implementada na identificação e registo de indicadores tafonómicos presentes nas superfícies dos restos. Marcas de processamentos e/ou consumo, antropogénico ou por outros animais, foram descritas através do registo da localização, morfologia e intensidade de indicadores de fractura (e.g., fractura por flexão ou percussão), marcas de corte (e.g., incisões, golpes), marcas de dentes (e.g., mordiscos, depressões) (Binford, 1978, 1981; Brain, 1981) e termo-alterações (Stiner \& alii, 1995; Solari \& alii, 2015).

Outros indicadores foram registados consoante o seu grau de afectação (Almeida, 2017), nomeadamente a presença de vermiculações, meteorização (Behrensmeyer, 1978), pisoteio, precipitação de óxidos e formação de concreções.

\section{RESULTADOS}

O conjunto apresenta um NSP de 633 registos, tendo sido possível identificar taxonomicamente cerca de $15 \%$ do conjunto, com os restantes $85 \%$ a corresponderem a restos de mamíferos (Tabela 1). Bos sp. está presente sobretudo através de restos das extremidades apendiculares com destaque para as falanges proximais e mesiais, mas também para porções de mandíbulas (Tabela 2). Nesta análise, as sondagens 7 e 8 apresentavam restos de gado bovino que, tomados em conjunto, corresponderiam a um MNI de um adulto com mais de 36 meses de idade, como indicado pela porção distal de um metatarso com os côndilos fusionados e que sugere uma pequena dimensão do indivíduo em questão. Ainda nos ani- mais de maior porte, registou-se Cervus elaphus, circunscrito à sondagem 7 , através de um fragmento de um metacarpo, dois fragmentos de uma falange proximal e dois de um astrágalo, associáveis a um MNI de um adulto. (Tabela 1; Tabela 2)

As ovelhas e cabras, de difícil identificação específi$\mathrm{ca}$, foram maioritariamente agrupadas em Ovis/Capra, estando ausentes restos mais robustos que pudessem indiciar a presença de espécimes selvagens de Capra pyrenaica. Foi possível uma identificação mais precisa para dois fragmentos de um astrágalo de Ovis aries e um fragmento de chifre e dois dentes isolados de Capra hircus, resultando em um MNI de um adulto para cada, com mais de 40 meses de idade, aos quais acrescem um adulto ( $24 \mathrm{a} 48$ meses) e um juvenil (6 a 12 meses) de ovelha/cabra. Ainda que seja o grupo taxonómico melhor representado quantitativamente e no que respeita à diversidade de elementos dos diferentes segmentos anatómicos, de salientar que os valores para o esqueleto axial craniano se encontram sobre-representados devido ao alto número de dentes e fragmentos de dentes identificados, algo comum em conjuntos com estas cronologias e características. Efectivamente, existe uma relevante disparidade para o caso das ovelhas e cabras se considerarmos os valores NISP (48) e MNE (26) que se deverá maioritariamente à fragmentação de peças dentárias.

Sus sp. é o terceiro grupo taxonómico melhor representado, atrás do gado bovino e das ovelhas/cabras. A ausência de elementos mensuráveis que permitissem uma identificação específica é de relevar, ainda que não se tenham registado restos sugestivos de um grande porte e, como tal, da presença da espécie selvagem. À semelhança do sugerido (Dias $\mathscr{\&}$ alii, no prelo), os escassos elementos mensuráveis apontam para animais de pequenas dimensões pelo que provavelmente se tratarão de Sus scrofa domesticus. Uma vez mais, destaca-se a presença de restos do esqueleto axial craniano, especialmente de fragmentos de dentes isolados, que pela análise das idades de erupção e desgaste indicam um MNI de três indivíduos, correspondendo a um sub-adulto (18 a 30 meses), um adulto (30 a 72 meses) e um adulto/ senil (52 a 95 meses).

Foi identificada uma mandíbula de um Oryctolagus cuniculus adulto na sondagem 1 e um processo transverso de uma vértebra de Leporidae na sondagem 8. Como discutido, de uma forma geral fica demonstrada a relevância de dentes e elementos das patas des- 
tes animais, em detrimento do esqueleto axial pós-craniano e de elementos apendiculares associados a um maior aporte cárnico (Tabela 2). Entre os restos apenas identificados por grupo de peso, deixando de lado os considerados como desconhecidos, verifica-se a escassez de registos de porte muito pequeno, alguma abundância de restos de animais de porte médio a grande e um predomínio de animais de porte pequeno, com entre 20 a $100 \mathrm{~kg}$. Os últimos, que poderiam ser associados a ovelhas/cabras ou animais de porte similar, apresentam alguns elementos correspondentes às partes anatómicas menos representadas, assim como um importante número de fragmentos de ossos longos (sobretudo diáfises). Para além disso, é clara a baixa frequência de restos de ossos planos, os quais estão igualmente pouco representados nos registos identificados taxonomicamente e que se estende aos animais de porte $>100 \mathrm{~kg}$. O conjunto é composto por 161 fragmentos com

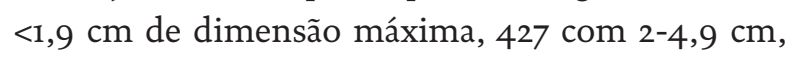
41 com 5-7,9 cm e 4 com 8-10cm, ou seja, 92,9\% do conjunto tem $<4,9 \mathrm{~cm}$ face a $7,1 \% \mathrm{com}>5 \mathrm{~cm}$. Fica comprovada a baixa preservação da amostra analisada, sobretudo tendo em conta a frequência de espécies de porte muito pequeno que poderiam inflacionar os restos de menores dimensões. De referir a quase ausência de elementos completos (o,3\%), ainda que a fragmentação moderna também deva ser mencionada (43,8\%).

De forma a melhor compreender a fracturação/ fragmentação do conjunto foi realizada a análise da completude diafisária em 85 restos e dos planos de fractura diafisários em 121 fragmentos com 312 planos (Figura 2). Verifica-se um predomínio de registos com $<50 \%$ da longitude diafisária preservada, entre estes destacando-se os que têm $<25 \%$; e uma maior frequência de $<25 \%$ da secção diafisária preservada. De salientar os valores altos de delineações longitudinais, ângulo rectos e uma ligeira maior abundância das superfícies suaves face às superfícies irregulares (Figura 2).

No que respeita aos indicadores de processamento e consumo das carcaças de animais, apesar da baixa preservação do conjunto foi possível identificar uma importante frequência de restos com marcas de corte e indicadores de fracturação dinâmica antropogénica, queima e de forma menos expressiva a possível fervura (Tabela 3; Figura 3).

As marcas de corte foram registadas em restos de Bos taurus, nomeadamente uma falange proximal com golpes paralelos, um calcâneo com incisões oblíquas paralelas, um metatarso com uma incisão isolada oblíqua e um fragmento de mandíbula com incisões isoladas e agrupadas paralelas no colo do processo condilar, relacionáveis com actividades de descarne e desarticulação, ainda que no caso da mandíbula possa associar-se à remoção da língua. Uma incisão isolada em astrágalo de Cervus elaphus, outra em diáfise de fémur de Ovis/Capra e várias incisões paralelas em calcâneo e mandíbula de Sus sp., sugerem a existência de actividades de processamento similares às supramencionadas para os restos de bovídeo. Contudo, a maioria dos registos com marcas de corte foram considerados indeterminados taxonomicamente, englobando animais de porte indeterminado (6), pequeno (5), pequeno/médio (2), médio (1) e grande (1), correspondendo a costelas (4), ossos longos (5) e planos (5) ou indeterminados (1), relacionáveis com desconexão/descarne, remoção de vísceras e segmentação (Tabela 3).

A fracturação antropogénica está representada por um impacto isolado em rádio de Ovis/Capra e fragmentos diafisários de animais de porte similar, uma extração cortical em metatarso de Bos sp. restos indeterminados de animais de porte pequeno a grande (7), ocasionalmente associados a outros estigmas como fissuras e possíveis contragolpes, tendo-se identificado um cone de percussão em diáfise de porte médio/grande (23,41x17,03 mm).

A termo-alteração por queima é relevante no conjunto, sobretudo nas sondagens 7 e 8 onde correspondem a cerca de $26 \%$ e $56 \%$ do total de restos com este indicador tafonómico. Fragmentos de astrágalo de Cervus elaphus e de Ovis aries e Ovis/Capra têm grau 2 de queima, com 1 dos fragmentos de astrágalo de veado a atingir o grau 3 de carbonização. Os restantes são registos indeterminados taxonomicamente, sobretudo fragmentos de ossos longos (24) e indeterminados (18) de porte indeterminado (23) e pequeno (15), com graus iniciais de afectação (Grau 1 e $2=24$ ), mas também carbonização (15) e, inclusive, mais avançados atingindo a calcinação (Grau 4 e $5=11$ ). A possível fervura é escassa e circunscrita a restos indeterminados taxonomicamente. Dias $\mathbb{\&}$ alii (no prelo) haviam também indicado a relevância de restos queimados nos materiais das sondagens 1 e 3 (Figura 3).

Quanto à presença de marcas de dentes, está circunscrita a perfurações opostas em planos de fractura de diáfise de animal de porte pequeno, rádio de Ovis/ 
Capra com mordiscos na diáfise e mordiscos e depressões espalhados pela diáfise e epífise do metatarso de Bos sp., as últimas morfologicamente relacionáveis com um carnívoro, provavelmente um grande canídeo. A comparação métrica demonstra que os mordiscos no metatarso de Bos sp. (OC-BT) apresentam dimensões similares a canídeos e suídeos, diferenciando-se das amostras antrópicas principalmente em tecido cortical (Figura 4). Os mordiscos no rádio de Ovis/Capra, apresentam comprimentos comparáveis a amostras com marcas de dentes de canídeos, suídeos e humanas, mas os valores obtidos para a largura parecem ter mais similitudes com as amostras de canídeos, nomeadamente Canis lupus familiaris obtidas por Andrés \& alii (2012) (Figura 4). Os restantes indicadores englobam registos vestigiais de acção hídrica e pisoteio que não foram relevantes nos contextos em estudo. A meteorização e vermiculações assumem alguma importância estando presentes em $>20 \%$ do conjunto. A meteorização foi registada principalmente em grau $1(50,4 \%)$ e 2 $(29,6 \%)$, ainda que graus mais avançados também ocorram: graus $3(17,8 \%)$ e 4 ( $2,2 \%)$. As vermiculações seguem um padrão similar, mas com ausência de grau 4 e destacando-se ainda mais a afectação de grau $1(81,7 \%)$ comparativamente aos graus $2(12,4 \%)$ e $3(5,9 \%)$.

\section{DISCUSSÃO}

Dias $\&$ alii (no prelo) estudou uma amostra de materiais das sondagens 1 e 3 do Outeiro do Circo, tendo identificado uma maior frequência de restos de Ovis/Capra, seguidas por Bos e Sus, com os registos de Cervus elaphus, Canis lupus familiaris, Equus e Lepus a terem menos expressividade. De forma similar ao sucedido, registamos uma predominância de espécies domesticadas faces às selvagens, estando ausentes os restos de Bos primigenius ou Sus scrofa entre os registos mensuráveis. Tudo parece apontar para a presença única de Bos taurus e Sus scrofa domesticus entre os restos mensuráveis e os restantes apresentam pequenas dimensões que são concordantes com esta possibilidade. Salienta-se que não identificamos qualquer elemento de canídeo, algo que havia acontecido anteriormente com base na presença de uma mandíbula e dois dentes recolhidos na Sondagem 1, ou de equídeo que havia sido identificado por uma pélvis e um dente da mesma área (Dias \& alii, no prelo).
Quanto aos padrões de idade, verifica-se um predomínio de indivíduos adultos no total do conjunto existente como demonstrado pela presença de ossos fusionados e dentição permanente com desgaste. Alguns indivíduos mais jovens foram registados em ambos os estudos, nomeadamente no caso de Sus sp. e Ovis/Capra, com Dias $\&$ alii (no prelo) a identificarem um Bos sp. juvenil entre os materiais da Sondagem 3.

A importância de ossos do esqueleto apendicular havia sido indicada, tendo-se sugerido que elementos menos densos poderiam não ter sobrevivido ao atrito diagenético. Efectivamente, Bos sp. estava representado quase unicamente por peças dentárias e mandibulares, porém Cervus elaphus também apresentava alguns ossos longos. Ovis/Capra e Sus sp., apesar de representados principalmente por dentes isolados e mandíbulas, também tinham registos das porções superiores apendiculares, num padrão que se apresenta similar ao aqui apresentado, ainda que com menos ossos das extremidades. Estes, agora registados de forma comparativamente abundante, são provenientes essencialmente das sondagens $7 \mathrm{e}$ 8 , ou seja, próximas do talude defensivo.

Do ponto de vista tafonómico, os únicos ossos considerados como tendo uma pátina sugestiva de serem intrusões são provenientes da sondagem 1 , o que nos parece compreensível dada a própria formação deste registo, correspondente a uma muralha compósita, com abundantes clastos e remobilizações (Figura 5). Os restos com indicadores de processamento (marcas de corte, fractura antropogénica) estão divididos pelas várias sondagens, salientando-se as marcas de corte nas sondagens 7 e 8 . Não obstante, enquanto $5,5 \%$ e $3,8 \%$ dos restos das sondagens 7 e 8 apresentam respectivamente marcas de corte, na sondagem 3 esse valor baixa para $0,6 \%$ e na 1 sobe para $7,5 \%$. Nas sondagens 3 e 7 destaca-se a fracturação antropogénica, sobretudo na sondagem 3 que engloba cerca de $42 \%$ dos restos com estes indicadores. Porém, em proporção, apenas $0,9 \%$ dos restos dessa sondagem estão queimados, enquanto nas restantes sondagens esse valor oscila entre os $2 \%$ da sondagem 7 e os $2,8 \%$ da sondagem 3 .

A termo-alteração por queima e possível fervura são mais abundantes na sondagem 8 onde $14,6 \%$ dos restos estão queimados. Nas restantes sondagens os valores oscilam entre $5 \%$ na sondagem 1 e os $2 \%$ da sondagem 7. A exposição ao fogo terá sido relevante entre os materiais analisados anteriormente $\mathrm{e}$ 
provenientes das sondagens 1 e 3 , tendo-se registado restos carbonizados, alguns dos quais recolhidos em unidades com carvões à semelhança do aqui descrito (Dias $\mathbb{E}$ alii, no prelo).

Compreender se os restos foram queimados durante o tratamento culinário, devido ao uso como combustível, se foram atirados para o fogo como desperdício ou queimados acidentalmente é difícil. Os animais podem ser grelhados sem grande processamento (Kent, 1993), com excepções como costelas e outros elementos axiais (Oliver, 1993). Mesmo quando os grelhados são a principal forma de tratamento culinário a representatividade de ossos queimados poderá ser bastante reduzida (Kent, 1993, p. 348). Existem diferenças na combustão consoante $o$ tipo de osso com o tecido esponjoso a ser mais combustível que o cortical (de relembrar a baixa presença de restos de ossos planos identificados ou não taxonomicamente no conjunto analisado), teor de humidade e grau de fragmentação (e.g., Théry-Parisot $\&$ alii, 2005). No conjunto do Outeiro do Circo foi registada queima em vários astrágalos o que poderia indicar a remoção das extremidades apendiculares previamente ao tratamento culinário de porções maiores. A presença de graus iniciais de afectação por queima e colorações duplas parece também sugerir o tratamento culinário, mas a presença de carbonização e calcinação poderia estar associada à acção de alimentar o fogo ou de o utilizar como forma de lidar com desperdícios. Dadas as evidências parece-nos parcimoniosa uma interpretação na qual os restos queimados se associam maioritariamente ao tratamento culinário, com as restantes hipóteses a desempenharem um papel secundário.

Quanto às marcas de dentes, apenas se verificam na sondagem 7 , ficando atestada uma baixa incidência de dano causado por carnívoros no conjunto analisado. Isto poderá contrastar com o expectável visto se tratar de um tipo de ocupação alargada, se ter identificado a presença de cão (e suínos) e algumas das marcas de dentes serem associáveis morfologicamente e metricamente à acção de um canídeo. Subsiste a possibilidade de estes restos estarem maioritariamente associados a um comportamento que dificultasse o acesso por carnívoros, sendo também de ter em conta que a frequência de marcas de dentes criadas por canídeos poderá variar consideravelmente devido à frequência na qual têm acesso aos ossos, ao tipo de tratamento culinário, tamanho e densidade dos restos (Binford, 1981; Kent, 1981, 1993).
A meteorização encontra-se dividida entre as sondagens com uma maior quantidade de restos. Quanto a abundâncias relativas ao número de registos por sondagem, a meteorização encontra-se em cerca de $17 \%$ dos restos da sondagem 8 , com as restantes sondagens a terem entre 22 e $25 \%$ dos restos afectados, o que sugere uma mais rápida sedimentação nas sondagens 1,3 e 7 comparativamente à sondagem 8 . Não obstante, seria necessária uma maior amostra ou uma diferença significativa para melhor discutir essa possibilidade, assim como estender a análise aos restantes elementos das sondagens 1 e 3 . Seria interessante, por exemplo, comparar estes dados com aqueles provenientes de uma análise à fracturação das cerâmicas comparando os resultados obtidos e verificando a validade desta hipótese. As vermiculações são mais abundantes nas sondagens $7 \mathrm{e}$ 8, salientando-se a sua baixa representatividade na sondagem 3 apesar da relevância quantitativa dessa amostra. Também na sondagem $8,34,7 \%$ dos restos apresentam vermiculações o que, em conjunto com a meteorização mais baixa, poderia uma vez mais sugerir alguma diferença na formação deste ambiente sedimentar.

No que concerne à relevância do conjunto faunístico do Outeiro do Circo para a compreensão das dinâmicas económicas do ponto de vista faunístico durante o final da Idade do Bronze, não existem muitos contextos, sobretudo com intervenções recentes e relevância quantitativa, que permitam uma comparação sustentada. Deixando de parte conjuntos publicados de realidades arqueológicas ou geográficas mais afastadas e, como tal, focando as informações existentes para a faixa que vai desde o interior alentejano português à Extremadura contamos apenas com alguns conjuntos englobados na Idade do Bronze e início da Idade do Ferro (Figuras 6 e 7).

Restringindo-nos aos conjuntos com um NISP $>50$, para a Idade do Bronze inicial apenas poderemos referir Los Barruecos (Malpartida de Cáceres) e, para a fase plena Alange (Badajoz), sendo que em ambos os contextos se denota a predominância de ovelhas/cabras e gado bovino, com uma melhor representatividade dos suínos face aos bovinos em Los Barruecos. Equídeos apenas se identificam em Los Barruecos, com a caça de cervídeos a ser reduzida neste sítio e residual em Alange. Durante o final da Idade do Bronze, o Castro de Ratinhos (Moura) e o Outeiro do Circo (Beja) apresentam abundâncias relativas similares, com predomínio de ovelhas/ca- 
bras, seguidas por gado bovino, suíno e cervídeos. Em Alange, pelo contrário, o gado bovino é maioritário, com boas representatividades de ovelhas/cabras e suínos e, como nos restantes, baixos valores de cervídeos. Saliente-se a existência de equídeos no Outeiro do Circo que, possivelmente, se tratará de Equus cf. asinus (Dias \& alli, no prelo).

Com o início da Idade do Ferro o número de conjuntos na zona em estudo aumenta, ainda que com algumas disparidades a nível de amostras passíveis de comparação. A presença escassa de equídeos verifica-se também na Idade do Ferro antigo de Cabeço Redondo (Moura), onde ovelhas/cabras são mais abundantes, seguidas por gado bovino e suíno e, uma vez mais, escassez de cervídeos. Ainda que com um conjunto mais pequeno, de salientar que apenas no Castro da Azougada (Moura) (Nabais $\mathbb{8}$ Soares, 2017) se verifica a predominância de cervídeos face aos restantes grupos. Sítios como Medellín (Badajoz), Sierra del Aljibe (Aliseda, Cáceres) e Alcazaba de Badajoz (Badajoz) demonstram um maior desenvolvimento de práticas assentes no gado bovino, sobretudo em Sierra del Aljibe, com menos abundâncias de cervídeos e suínos face às ovelhas/cabras, ainda que em Alcazaba de Badajoz exista um maior equilíbrio entre estes dois grupos. La Mata (Campanario, Badajoz), apresenta o conjunto quantitativamente mais relevante, com um predomínio destacado de gado bovino, seguido por ovelhas/cabras e frequências mais reduzidas mas similares de suínos, cervídeos e equídeos.

\section{CONCLUSÕES}

O conjunto faunístico do Outeiro apresenta uma relevância de gado bovino, caprino e suíno atestando a importância do desenvolvimento agro-pecuário durante o final da Idade do Bronze. A aquisição de produtos primários e secundários (lã, leite, tracção) terá sido uma constante na vida destes grupos para os quais as práticas cinegéticas, nomeadamente a caça de veado e, eventualmente, de outras espécies como o javali, coelho e lebre, teriam um papel secundário. Registaram-se indicadores variados de desmanche e processamento dos restos de animais de diferentes portes, com os grelhados aparentemente a destacar-se como prática culinária de eleição.

Fica em aberto a possibilidade de se verificarem diferentes representatividades anatómicas ou até de espécies consoante a zona do povoado, sendo que junto ao talude defensivo as evidências são sugestivas de se tratar de uma zona de despejo tipo "lixeira", ou de acumulação de detritos resultantes de escorrências na encosta do povoado. Com o prosseguimento dos trabalhos arqueológicos e das análises de eventuais novos restos arqueofaunísticos será possível aumentar o leque de informação existente para esta região num período para o qual o Outeiro do Circo se assume de enorme relevância devido à escassa informação arqueofaunística.

\section{BIBLIOGRAFIA}

ALMEIDA, Nelson J. (2017) - Zooarqueologia e tafonomia da transição para a agro-pastorícia no baixo e médio vale do Tejo. Mação: Instituto Terra e Memória.

ANDRÉS, M.; GIDNA, A. O.; YRAVEDRA, J.; DOMÍNGUEZ-RODRIGO, M. (2012) - A study of dimensional differences of tooth marks (pits and scores) on bones modified by small and large carnivores. Archaeological and Anthropological Sciences. 4, pp. 209-219.

BEHRENSMEYER, A. K. (1978) - Taphonomic and ecologic information from bone weathering. Paleobiology. 4:2, pp. 150-162.

BINFORD, L. (1978) - Nunamiut Ethnoarchaeology. New York: Academic Press.

BINFORD, L. (1981) - Bones: ancient men and modern myths. New York: Academic Press.

BINFORD, L. (1984) - Faunal remains from Klassies River Mouth. New York: Academic Press.

BRAIN, C. K. (1981) - The Hunters or the Hunted? An Introduction to African Cave Taphonomy. Chicago: University Press.

CARDOSO, J. L.; SOARES, R. (2013) - Faunas mamalógicas do sítio pós-orientalizante do Cabeço Redondo (Sobral da Adiça, Moura). Escavações de 2011. Al-Madan. 18, pp. 87-92.

CASTAÑOS, P. (1998a) - Evolución de las faunas protohistóricas en Extremadura. In RODRÍGUEZ DÍAZ, A., coord. - Extremadura Protohistórica: Paleoambiente, Economía y Poblamiento. Cáceres, p. 63-72.

CASTAÑOS, P. (1998b) - Estudio arqueozoológico de la fauna del Cerro del Castillo de Alange (Badajoz). In PAVÓN SOlDEVILA, I., ed. - El Cerro del Castillo de Alange (Badajoz). Intervenciones arqueológicas (1993). Mérida, p. 167-177.

CASTAÑOS, P. (1999) - Estudio de la fauna de la Sierra del Aljibe (Aliseda, Cáceres). In El poblado protohistorico de Aliseda (Cáceres). Campaña de 1995. Cáceres, p. 214-219.

CASTAÑOS, P. (2004) - Fauna y prácticas ganaderas. In Rodríguez Díaz, A., ed. - El edificio protohistórico de "La Mata" (Campanario, Badajoz) y su estudio territorial. Cáceres: Universidad de Extremadura, p. 453-467. 
DAVIS, S. J. M. (1996) - Measurements of a group of adult female Shetland sheep skeletons from a single flock: a baseline for zooarchaeologists. Journal of Archaeological Science. 23, pp. 593-612.

DELANEY-RIVERA, C.; PLUMMER, T. W.; HODGSON, J. A.; FORREST, F.; HERTEL, F.; OLIVER, J. S. (2009) - Pits and pitfalls: taxonomic variability and patterning in tooth mark dimensions. Journal of Archaeological Science. 36, pp. 2597-2608.

DRIESCH, A. (1976) - A guide to the measurement of animal bones from Archaeological sites. Harvard. Peabody Museum Bulletin 1.

GRAYSON, D. (1984) - Quantitative Zooarchaeology. London: Academic Press.

GRANT, A. (1982) - The use of tooth wear as guide to the age of domestic ungulates. In WILSON, B.; GRIGSON, C.; PAYNE, S., eds. - Ageing and sexing animal bones from archaeological sites. Oxford: Archaeopress, p. 91-198.

DIAS, I.; PORFÍRIO, E.; SERRA, M.; DETRY, C. (no prelo) - Late Bronze Age faunal remains fom Outeiro do Circo (Beja, Portugal): a preliminary study. In VALENTE, M. J.; DETRY, C.; COSTA, C., eds. - New Trends in Iberian Zooarchaeology. Oxford: Archaeopress.

KENT, S. (1981) - The dog - Archaeologists' best friend or worse enemy: spatial distribution of faunal remains. Journal of Field Archaeology. 8: 3, pp. 367-372.

KENT, S., (1993) - Variability in faunal assemblages: the influence of hunting skill, sharing, dogs, and mode of cooking on faunal remains at a sedentary Kalahari community. Journal of Anthropological Archaeology. 12, pp. 323-385.

LEMOINE, X.; ZEDER, M. A.; BISHOP, K. J.; RUFOLO, S. J. (2014) - A new system for computing dentition-based age profile in Sus scrofa. Journal of Archaeological Science. 47, pp. 179-193.

LIESAU, C.; GARCÍA, J. (2010) - La fauna de Ratinhos: estudio de la fauna y de la industria ósea procedente de la Tercera línea de muralla. In BERROCAL-RANGEL, L.; SILVA, A.C., eds. - O Castro dos Ratinhos (Barragem de Alqueva, Moura). Escavação num povoado proto-histórico do Guadiana, 2004-2007. Lisboa: Museu Nacional de Arqueologia, pp. 329-348.

LYMAN, R. L. (1994) - Vertebrate Taphonomy. Cambridge: University Press.

MORALES, A. (1977) - Los restos animales del castro de Medellín. In ALMAGRO-GORBEA, M., eds. - El Bronce Final y el Período Orientalizante en Extremadura. Biblioteca Praehistórica Hispana XIV Madrid, pp. 513-519.

NABAIS, M.; SOARES, R. (2017) - Zooarchaeological evidence from the Iron Age site of Castro da Azougada (Moura, Portugal). Revista Portuguesa de Arqueologia. 20, pp. 61-69.
OLIVER, J. S. (1993) - Carcass processing by the Hadza: bone breakage from butchery to consumption. In HUDSON, J., ed. - From bones to behavior: ethnoarchaeological and experimental contribution to the interpretation of faunal remains. Carbondale: Southern Illinois University Press, p. 200-228.

PAYNE, S. (1987) - Reference codes for wear states in the mandibular cheek tooth of sheep and goats. Journal of Archaeological Science. 14, pp. 6o9-614.

PAYNE, S.; BULL, G. (1988) - Components of variation in measurements of pig bones and teeth, and the use of measurements to distinguish wild from domestic pig remains. ArchaeoZoologia. II:1-2, pp. 27-66.

REITZ, E. J.; WING, E. S. (2008) - Zooarchaeology. Cambridge: University Press.

SALADIÉ, P. (2009) - Mossegades d'omnívors. Aproximació experimental i aplicació zooarqueològica a la Sierra de Atapuerca. Dissertação de Doutoramento. Universitat Rovira I Virgili.

SALADIÉ, P.; RODRÍGUEZ-HIDALGO, A.; DÍEZ, C.; MARTÍN-RODRÍGUEZ, P.; CARBONELL, E. (2013) Range of bone modifications by human chewing. Journal of Archaeological Science. 40, pp. 380-397.

STINER,M.;KUHN,S.;WEINER,S.;BAR-YOSEF,O.(1995) - Differential burning, recrystallization, and fragmentation of archaeological bone. Journal of Archaeological Science. 22, pp. 223-237.

SOLARI, A.; OLIVERA, D.; GORDILLO, I.; BOSCH, P.; FETTER, G.; LARA, V. H.; NOVELO, O. (2015) - Cooked bones? Method and practice for identifying bones treated at low temperature. International Journal of Osteoarchaeology. 25 , pp. 426-440.

VILLA, P.; MAHIEU, E. (1991) - Breakage patterns of human long bones. Journal of Human Evolution. 21, pp. 27-48.

THÉRY-PARISOT, I., COSTAMAGNO, S., BRUGAL, J.P., FOSSE, P., GUILBERT, R. (2005) - The use of bone as fuel during the Palaeolithic, experimental study of bone combustible properties. In MULVILLE, J.; OUTRAM, A.K., eds. - The Zooarchaeology offats, oils, milk and dairying. Oxbow Books, p. 50-59.

VALÉRIO, P.; SOARES, A.; ARAÚJO, F.; SILVA, R.; PORFÍRIO, E.; SERRA, M. (2013) - Estudo de metais e vestígios de produção do povoado fortificado do Bronze Final do Outeiro do Circo (Beja). In Arqueologia em Portugal 150 anos - Atas do I Congresso da Associação dos Arqueólogos Portugueses, 21 a 24 de Novembro de 2013. Lisboa: AAP, pp. 609-615.

ZEDER, M. A. (2006) - Reconciling rates of long bone fusion and tooth eruption and wear in sheep (Ovis) and goat (Capra). In RUSCILLO, D., ed. - Recent advances in ageing and sexing animal bones. Oxford: Oxbow Books, pp. 87-118. 
ZEDER, M.A.; LAPHAM, H.A. (2010) - Assessing the reliability of criteria used to identify postcranial bones in sheep, Ovis, and goats, Capra. Journal of Archaeological Science. 37: 11, pp. 2887-2905.

ZEDER, M. A.; PILAAR, S. E. (2010) - Assessing the reliability of criteria used to identify mandibles and mandibular teeth in sheep, Ovis, and goats, Capra. Journal of Archaeological Science. 37, pp. 225-242.

ZEDER, M. A.; LEMOINE, X.; PAYNE, S. (2015) - A new system for computing long-bone fusion age profiles in Sus scrofa. Journal of Archaeological Science. 55, pp. 135-150.

\begin{tabular}{|c|c|c|c|c|c|c|c|c|}
\hline Taxa & NISP & NISP\% & MNE & MNE\% & MNI & MNI\% & MNI Juvenil & MNI Adulto \\
\hline B & 15 & 2,4 & 14 & 23,7 & 1 & 10 & & 1 \\
\hline $\mathrm{CH}$ & 3 & 0,5 & 3 & 5,1 & 1 & 10 & & 1 \\
\hline $\mathrm{OA}$ & 2 & 0,3 & 1 & 1,7 & 1 & 10 & & 1 \\
\hline $\mathrm{O} / \mathrm{C}$ & 48 & 7,6 & 26 & 44,1 & 2 & 20 & 1 & 1 \\
\hline CE & 5 & 0,8 & 3 & 5,1 & 1 & 10 & & 1 \\
\hline S & 12 & 1,9 & 10 & 16,9 & 3 & 30 & 1 & 2 \\
\hline HER & 7 & 1,1 & & & & & & \\
\hline ORC & 1 & 0,2 & 1 & 1,7 & 1 & 10 & & 1 \\
\hline $\mathrm{L}$ & 1 & 0,2 & 1 & 1,7 & & & & \\
\hline${ }_{-}^{\mathrm{MA}}-$ & 539 & 85,2 & $-\quad-$ & $-\quad-$ & - & - & - & - \\
\hline GPind. & 274 & 50,8 & & & & & & \\
\hline$G P_{1}$ & 1 & 0,2 & & & & & & \\
\hline$G P_{1} / 2$ & 28 & 5,2 & & & & & & \\
\hline $\mathrm{GP} 2$ & 158 & 29,3 & & & & & & \\
\hline$G P 2 / 3$ & 30 & 5,6 & & & & & & \\
\hline$G P_{3}$ & 13 & 2,4 & & & & & & \\
\hline$G P_{3} / 4$ & 18 & 3,3 & & & & & & \\
\hline GP4 & 17 & 3,2 & & & & & & \\
\hline Total & 633 & 100 & 59 & 100 & 10 & 100 & 2 & 8 \\
\hline
\end{tabular}

Tabela 1 - Principais índices quantitativos aplicados na análise das faunas do Outeiro do Circo. Legenda: $\mathrm{B}=\mathrm{Bos}$ sp.; $\mathrm{CH}=\mathrm{Capra}$ hircus; OA = Ovis aries; O/C = Ovis/Capra; $\mathrm{CE}=$ Cervus elaphus; $\mathrm{S}=$ Sus sp.; HER = Herbívoro; ORC = Oryctolagus cuniculus; $\mathrm{L}$ = Leporidae; MA = Mamíferos; GP = Grupo de Peso. Os restos não identificados taxonomicamente são apresentados por Grupos de Peso. 


\begin{tabular}{|c|c|c|c|c|c|c|c|c|c|c|c|c|c|c|c|c|c|c|}
\hline Elemento & B & $\mathrm{CH}$ & $\mathrm{OA}$ & $\mathrm{O} / \mathrm{C}$ & CE & $\mathrm{S}$ & ART & ORC & $\mathrm{L}$ & GPo & GP1 & $\mathrm{GP} 1 / 2$ & $\mathrm{GP} 2$ & $\mathrm{GP}_{2} / 3$ & $\mathrm{GP}_{3}$ & $\mathrm{GP}_{3} / 4$ & $\mathrm{GP}_{4}$ & Total \\
\hline Haste/Chifre & & $1(1)$ & & & & & & & & 1 & & & & & & & & $2(1)$ \\
\hline Crânio (maxilar) & & & & $2(2)$ & & $1(1)$ & & & & 4 & & & 3 & & & 1 & & $11(3)$ \\
\hline Mandíbula & $4(3)$ & & & & & $2(1)$ & & 1 & & & & & 6 & & & & & $13(5)$ \\
\hline Incisivo solto & & & & $1(1)$ & & $2(2)$ & & & & & & & & & & & & $3(3)$ \\
\hline Pré-molar solto & $1(1)$ & $1(1)$ & & $2(2)$ & & & & & & & & & & & & & & $4(4)$ \\
\hline Molar solto & & $1(1)$ & & $31(10)$ & & $3(2)$ & 1 & & & & & & & & & & & $36(13)$ \\
\hline Dente ind. & & & & & & & 1 & & & 2 & & & & & & & & $3(0)$ \\
\hline Vértebra & & & & & & & & & $1(1)$ & & & 6 & 3 & 1 & & & & $11(1)$ \\
\hline Costela & & & & & & & & & & & & & 9 & 2 & & & 2 & $13(0)$ \\
\hline Escápula & & & & & & & & & & & & & 1 & & & & & $1(0)$ \\
\hline Úmero & & & & & & $1(1)$ & & & & & & 1 & 1 & & & & & $3(1)$ \\
\hline Rádio & & & & $2(2)$ & & & & & & & & & 1 & & & & & $3(2)$ \\
\hline Ulna & & & & & & & & & & & & & 1 & & & & & $1(0)$ \\
\hline Pélvis & & & & & & $1(1)$ & & & & & & & 1 & & & & & $2(1)$ \\
\hline Fémur & & & & $1(1)$ & & $1(1)$ & & & & & & & 2 & & & & & $4(2)$ \\
\hline Patela & $1(1)$ & & & & & & & & & & & & & & & & & $1(1)$ \\
\hline Tíbia & & & & $1(1)$ & & & & & & & & & & 1 & & & & $2(1)$ \\
\hline Metacarpo & & & & $3(2)$ & $1(1)$ & & & & & & & & & & & & & $4(3)$ \\
\hline Metatarso & $2(2)$ & & & I(1) & & & & & & & & & & & & & & $3(3)$ \\
\hline Metápodo & & & & & & & 3 & & & & & & & & & 1 & & $4(0)$ \\
\hline Astrágalo & & & $2(1)$ & $2(2)$ & $2(1)$ & & 2 & & & & & & & & & & & $8(4)$ \\
\hline Calcâneo & $1(1)$ & & & $1(1)$ & & I(1) & & & & & & & & & & & & $3(3)$ \\
\hline Carpal/tarsal & & & & & & & & & & & & 1 & & & & & & $1(0)$ \\
\hline Falange I & $2(2)$ & & & $1(1)$ & $2(1)$ & & & & & & & & & & & & & $5(4)$ \\
\hline Falange II & $3(3)$ & & & & & & & & & & & & & & & & & $3(3)$ \\
\hline Falange III & $1(1)$ & & & & & & & & & & & & & & & & & $1(1)$ \\
\hline Osso longo & & & & & & & & & & 7 & 1 & 5 & 113 & 23 & 13 & 12 & 15 & $189(0)$ \\
\hline Osso plano & & & & & & & & & & 87 & & 10 & 15 & & & 1 & & $113(0)$ \\
\hline Indeterminado & & & & & & & & & & 173 & & 5 & 2 & 3 & & 3 & & $186(0)$ \\
\hline Total & $15(14)$ & $3(3)$ & $2(1)$ & $48(26)$ & $5(3) 1$ & $12(10)$ & 7 & $1(1)$ & $1(1)$ & 274 & 1 & 28 & 158 & 30 & 13 & 18 & 17 & 633(59) \\
\hline
\end{tabular}

Tabela 2 - Number of Identified Specimens (NISP) e entre parêntesis Minimum Number of Elements (MNE) das faunas do Outeiro do Circo. Legenda: $\mathrm{B}=$ Bos sp.; $\mathrm{CH}=$ Capra hircus; $\mathrm{OA}=$ Ovis aries; $\mathrm{O} / \mathrm{C}=$ Ovis/Capra; $\mathrm{CE}=$ Cervus elaphus; $\mathrm{S}=$ Sus sp.; HER = Herbívoro; ORC = Oryctolagus cuniculus; $\mathrm{L}=$ Leporidae; MA = Mamíferos. Os números entre parêntesis correspondem ao MNE e os restos não identificados taxonomicamente são apresentados por Grupos de Peso. 


\begin{tabular}{lll} 
Indicador & $\mathrm{n}$ & $\%$ \\
\hline Marcas de corte & 23 & 3,6 \\
Fracturação antropogénica & 11 & 1,7 \\
Termo-alteração & 55 & 8,7 \\
?Fervura & 6 & 0,9 \\
Marcas de dentes & 3 & 0,5 \\
Acção hídrica & 1 & 0,2 \\
Meteorização & 135 & 21,3 \\
Vermiculações & 169 & 26,7 \\
Pisoteio & 2 & 0,3 \\
Fragmentação moderna & 277 & 43,8 \\
Pátina recente & 6 & 0,9 \\
Elementos completos & 2 & 0,3 \\
\hline
\end{tabular}

Tabela 3 - Principais indicadores tafonómicos registados nas faunas do Outeiro do Circo.
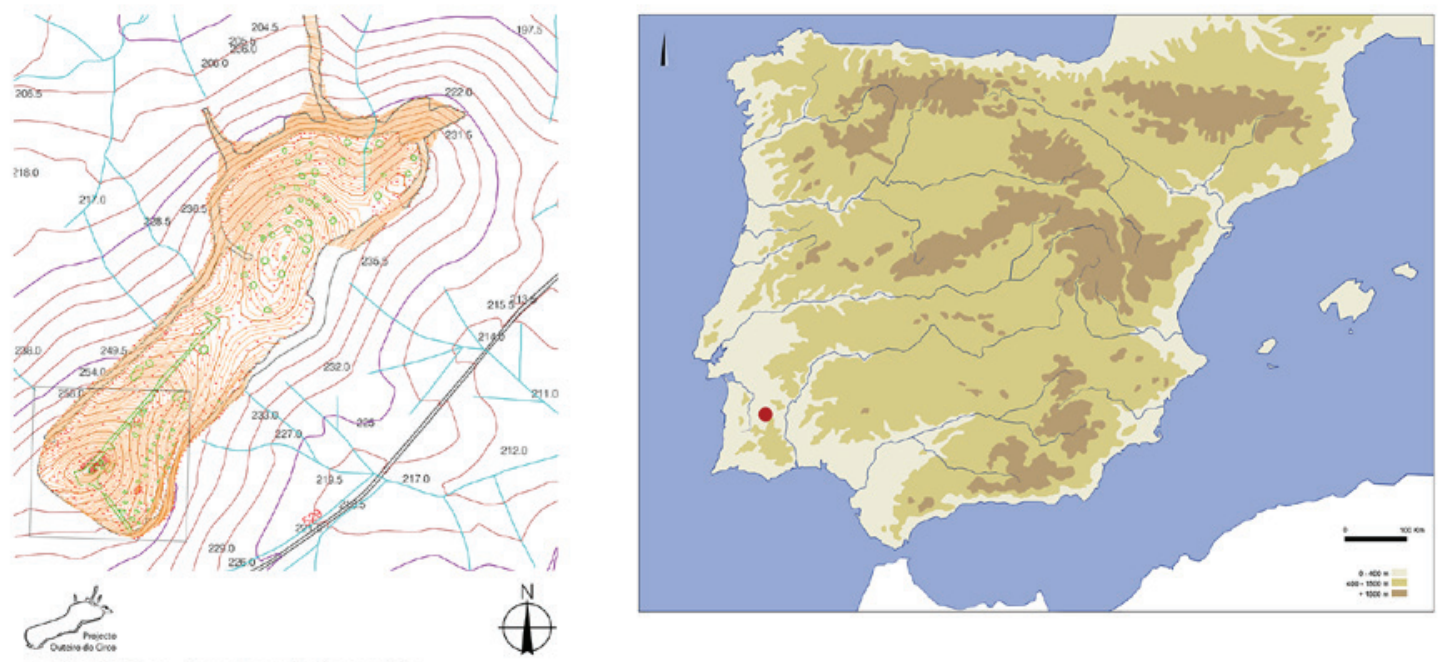

Outeiro do Circo - Levantamento Topográfico

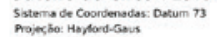

Escala 1:5000

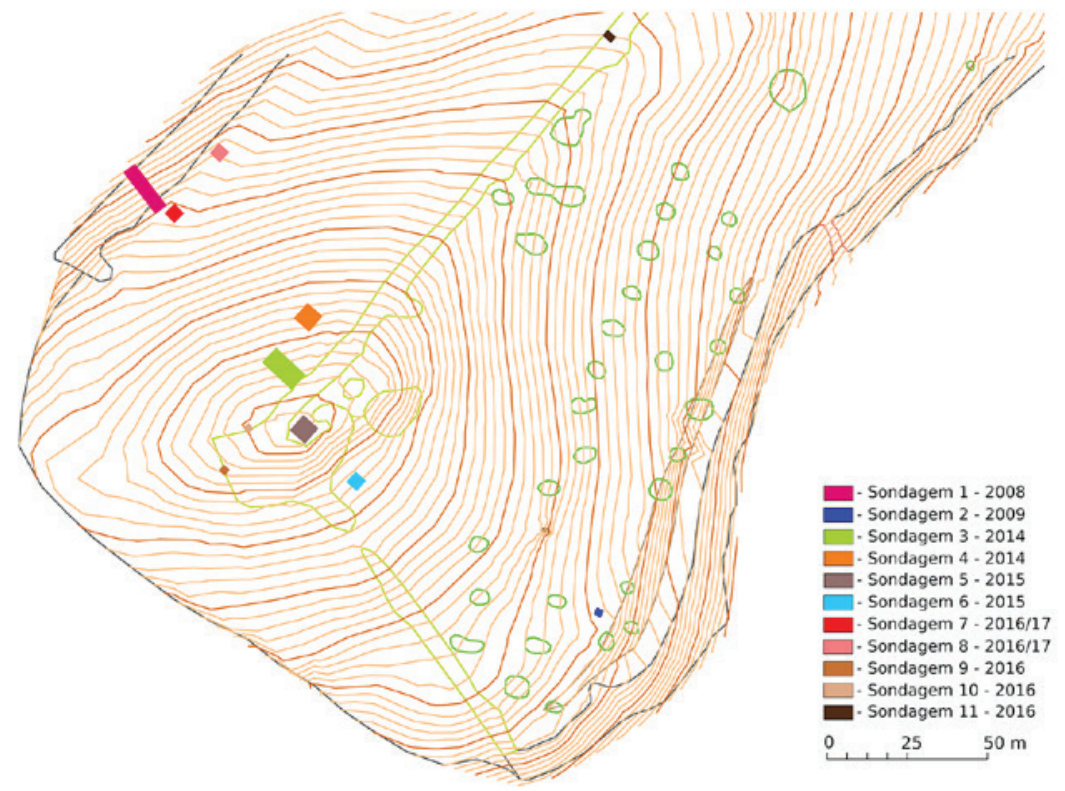

Figura 1 - Localização do Outeiro do Circo na Península Ibérica e levantamento topográfico com a localização das diferentes sondagens (2008-2017). 
Completude diafisária $(\%)$

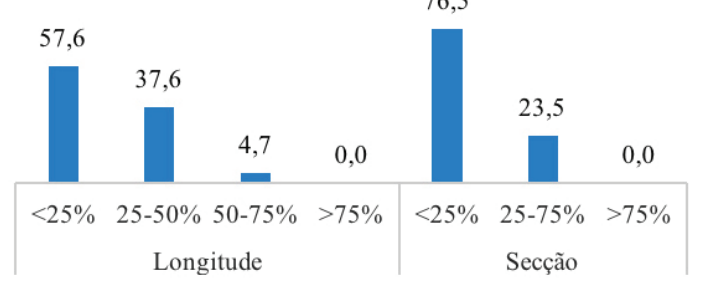

Planos de fractura $(\%)$

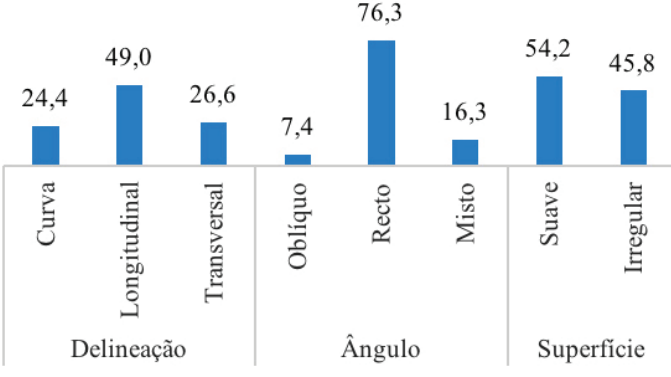

Figura 2 - Abundâncias relativas obtidas na análise da fractura e fragmentação das faunas do Outeiro do Circo para a completude diafisária consoante a longitude e secção (esquerda) e a delineação, ângulo e superfície de planos de fractura em tecido cortical (direita).

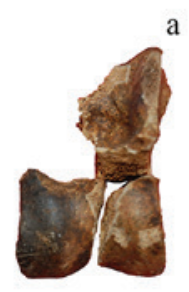

$\overline{\mathrm{cm}}$

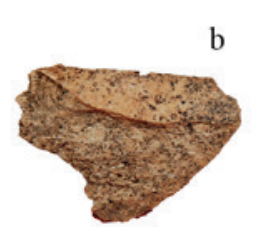

$\overline{1 \mathrm{~cm}}$

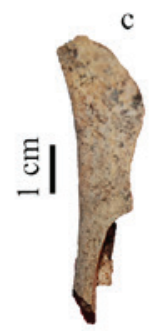

d
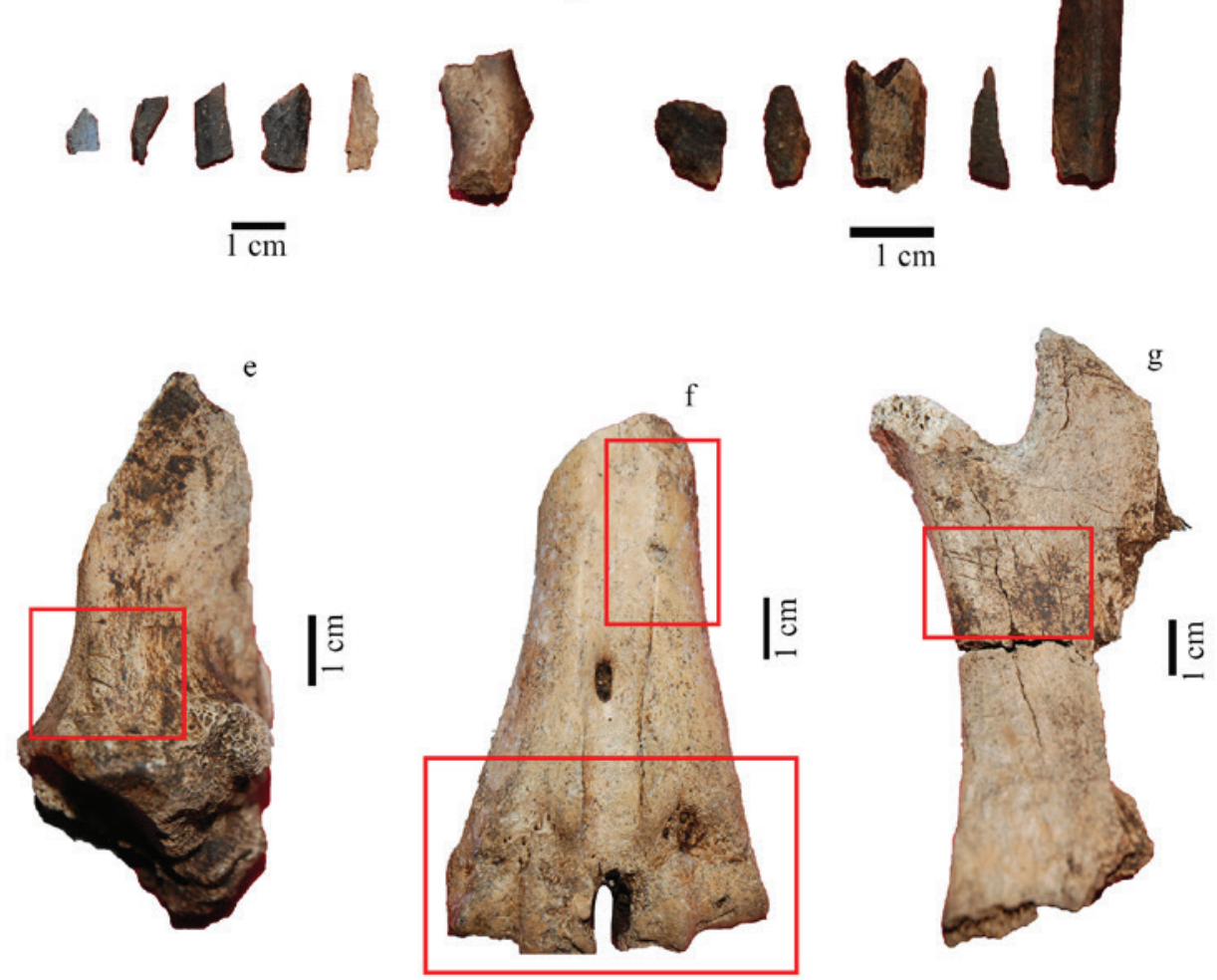

Figura 3 - Selecção de materiais do Outeiro do Circo: astrágalo de Cervus elaphus queimado (a), cone de percussão (b), fragmento diafisário com impactos de percussão antrópica (c), exemplos de ossos com dano de queima em diversos graus (d), calcâneo de Bos sp. com marcas de corte (e), metatarso de Bos sp. com marcas de dentes (f) e mandíbula de Bos sp. com marcas de corte (g). 
Comprimento canceloso

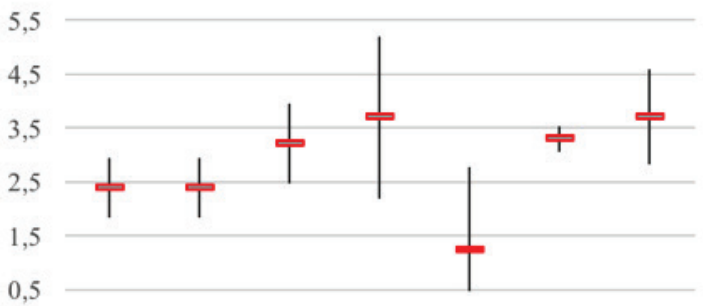

Largura canceloso

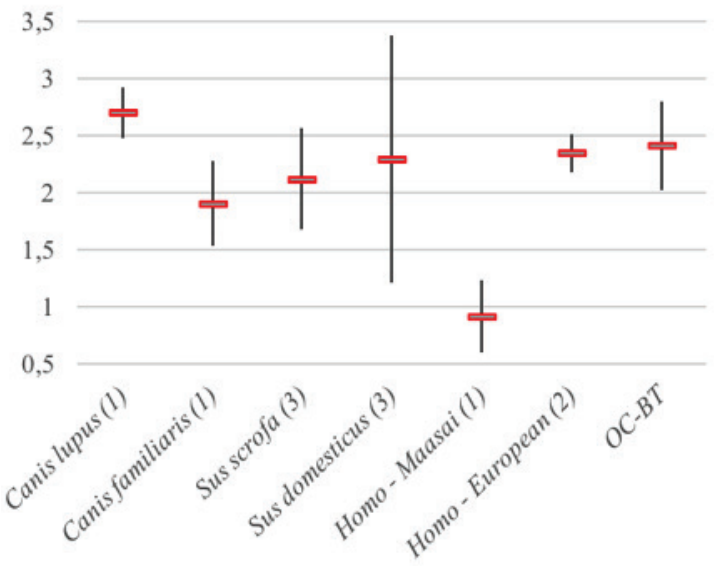

Comprimento cortical

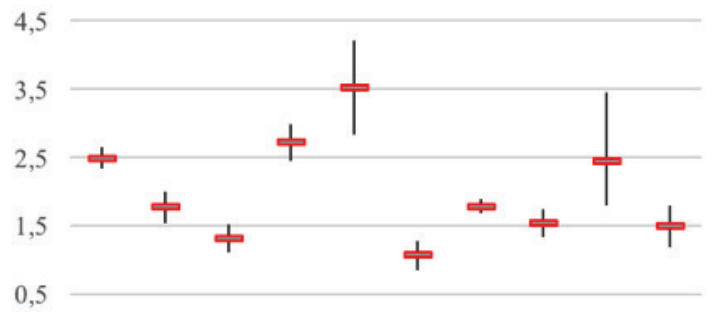

Largura cortical

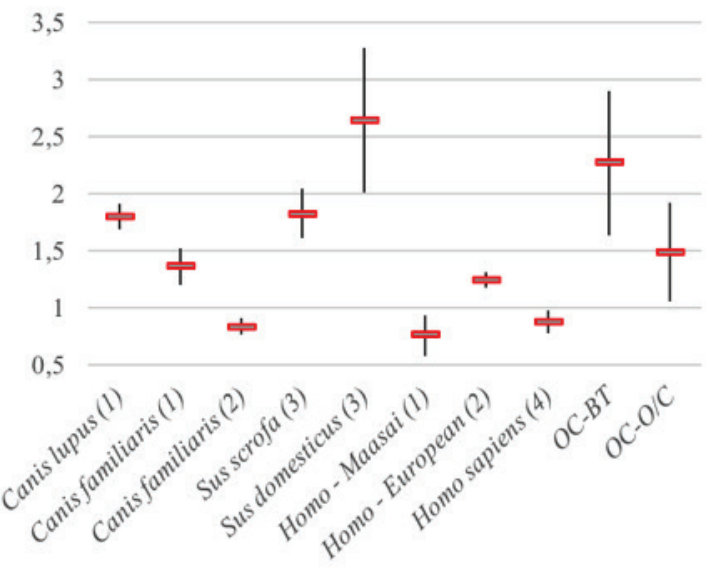

Figura 4 - Comparação dos valores obtidos (média e IC95\%) para as marcas de dentes obtidas em tecido canceloso e cortical nos materiais do Outeiro do Circo com dados publicados por (1) Andrés \& alii (2012), (2) Saladié \& alii (2013), (3) Saladié (2009) e (4) Delaney-Rivera \& alii (2009). Legenda: OC-BT = Outeiro do Circo - Bos taurus; OC-O/C = Outeiro do Circo-Ovis/Capra.

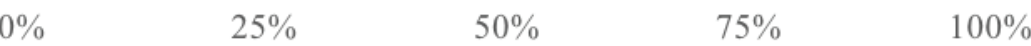

Marcas de corte (23)

Fractura antropogénica (12)

Queima (45)

(?)Fervura (6)

Marcas de dentes (3)

Meteorização (135)

Vermiculações (169)

Pátina recente (6)

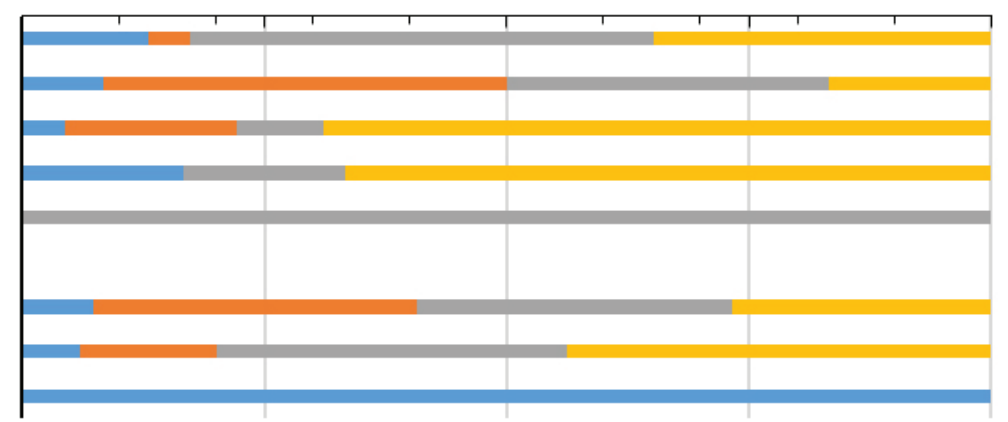

$\square \mathrm{S} 1 \quad \mathrm{~S} 3 \quad \mathrm{~S} 7 \quad \mathrm{~S} 8$

Figura 5 - Abundâncias relativas dos principais indicadores tafonómicos em relação à sua presença pelas sondagens do Outeiro do Circo analisadas no presente estudo. 


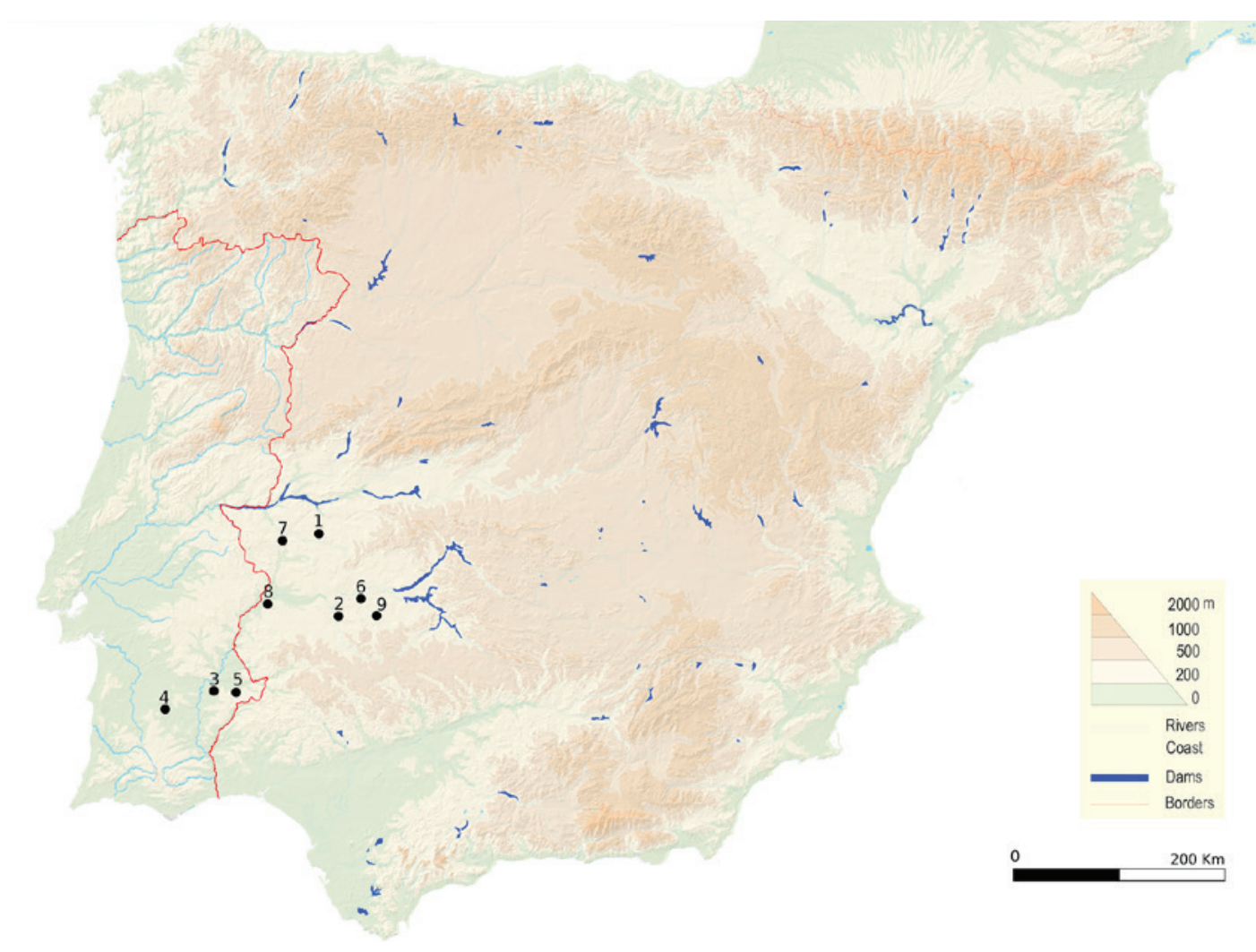

Figura 6 - Localização dos sítios mencionados no texto: 1 - Los Barruecos, 2 - Alange, 3 - Castro dos Ratinhos, 4- Outeiro do Circo, 5-Cabeço Redondo, 6-Medellín 77,7-Sierra del Aljibe, Aliseda, 8 - Alcazaba de Badajoz, 9 - La Mata. Base cartográfica de Luís Fraga da Silva, 2004, arqueotavira.com.

$\begin{array}{lllll}0 \% & 20 \% & 40 \% & 60 \% & 80 \%\end{array}$

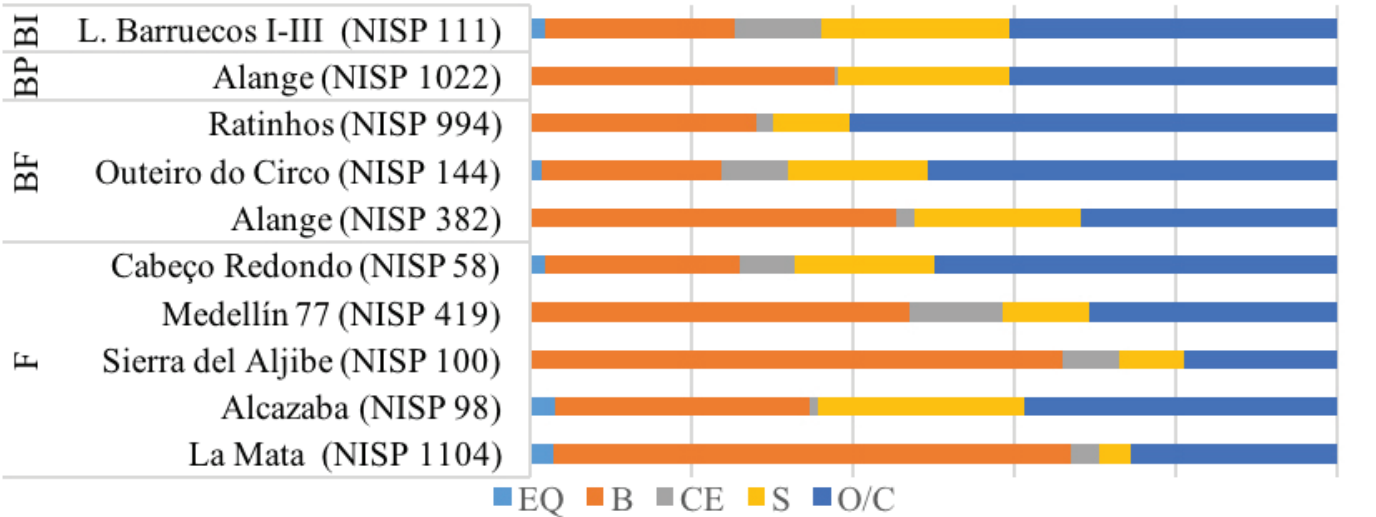

Figura 7 - Abundância relativa de Equus (EQ), Bos (B), Cervus (CE), Sus (S) e Ovis/Capra (O/C) para diferentes sítios do início da Idade do Bronze (BI), da fase plena da Idade do Bronze (BP), da fase final da Idade do Bronze (BF) e início da Idade do Ferro (F): Los Barruecos (Castaños, 1998a), Alange (Castaños, 1998b), Castro dos Ratinhos (Liesau \& García, 2010), Outeiro do Circo (Dias \& alii, no prelo e presente estudo); Cabeço Redondo (Cardoso \& Soares, 2013), Medellín 77 (Morales, 1977), Sierra del Aljibe, Aliseda (Castaños, 1999), Alcazaba de Badajoz (Castaños, 1998a), La Mata (Castaños, 2004). 



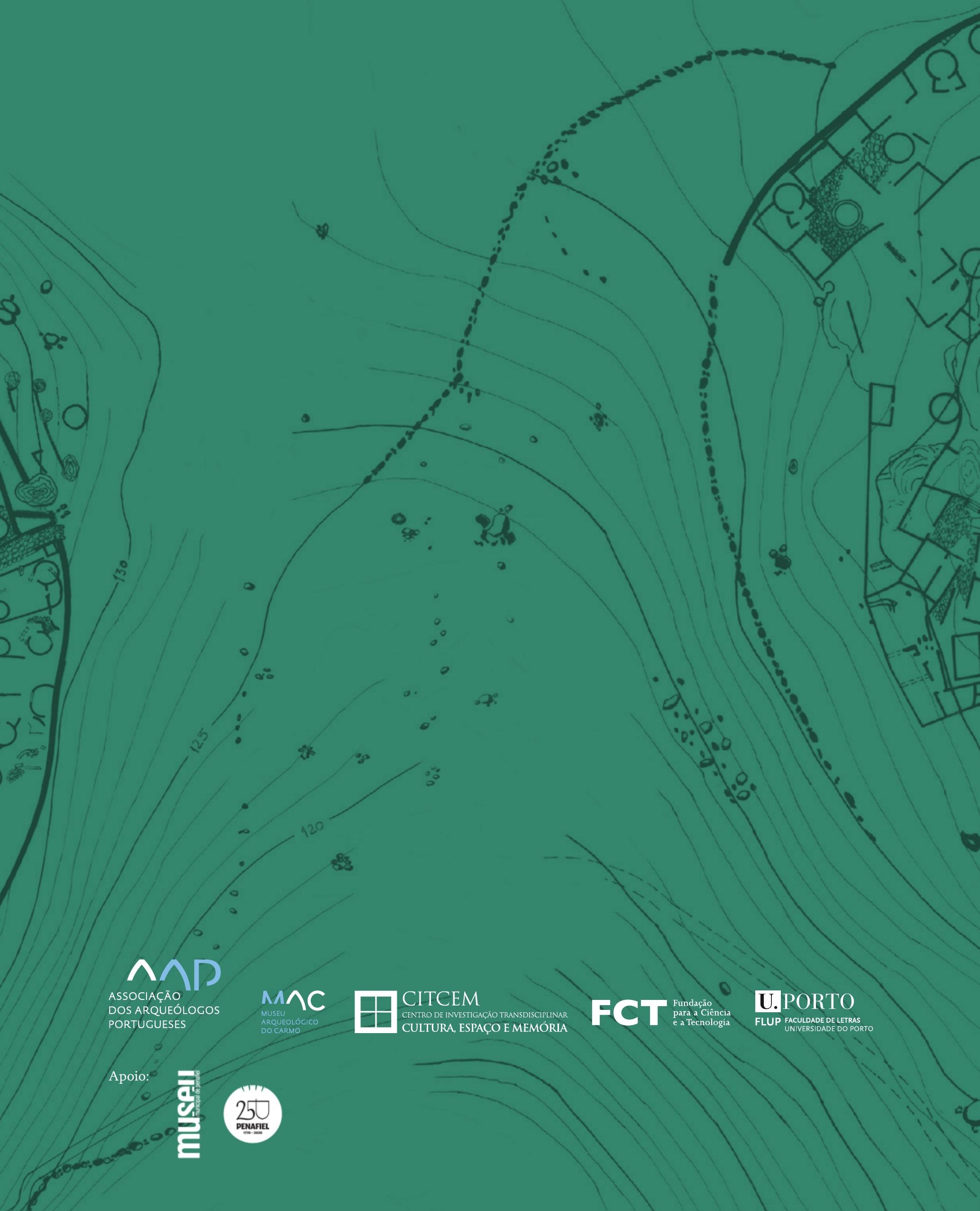

